\title{
Petrologia magnética do granito anorogênico Bannach, terreno granito- greenstone de rio Maria, Pará
}

\author{
José de Arimatéia Costa de Almeida ${ }^{1}$, Fabriciana Vieira Guimarães ${ }^{1} \&$ Roberto Dall'Agnol $^{2}$
}

\begin{abstract}
Resumo O Granito Bannach, de idade paleoproterozóica, é intrusivo em rochas arqueana do Terreno Granito-Greenstone de Rio Maria, sendo constituído por três fácies: monzogranitos de granulação grossa com anfibólio, biotita e, por vezes, clinopiroxênio; monzogranitos à biotita com textura porfirítica e leucomonzogranitos com textura variada. Magnetita, ilmenita, hematita, pirita, calcopirita, esfalerita e goethita são os minerais opacos identificados no corpo. A análise textural dos minerais óxidos de Fe e Ti permitiu reconhecer cinco formas distintas de ilmenita: 1- lamelas de exsolução nos cristais de magnetita (ilmenita treliça); 2 - lamelas espessas e contínuas no interior da magnetita (ilmenita sanduíche); 3 - cristais bem desenvolvidos, encontrados no interior de cristais de magnetita (ilmenita composta interna) ou em porções externas (ilmenita composta externa); 4 - manchas irregulares dentro dos cristais de magnetita (ilmenita em manchas); 5 - cristais isolados (ilmenita individual). Feições texturais sugerem que titanomagnetita, ilmenita composta interna e externa foram originadas durante o estágio precoce da cristalização. A ilmenita foi desestabilizada e parcialmente substituída por titanita ainda no estágio magmático. Durante o estágio subsólidus, a titanomagnetita foi afetada por processo de exsolução-oxidação e deu origem a intercrescimentos de magnetita quase pura com ilmenita (ilmenita treliça, mancha e sanduíche). A martitização da magnetita e a oxidação da pirita, gerando goethita, ocorreram a baixas temperaturas. Os valores mais elevados suscetibilidade magnética (SM) estão relacionados às fácies portadoras de anfibólio + biotita \pm clinopiroxênio e à fácies com porfirítica, as quais apresentam maiores conteúdos modais de opacos, anfibólio e total de máficos. As fácies leucograníticas apresentam menores valores de $\mathrm{SM}$ e de opacos. Há correlação positiva entre $\mathrm{SM}$ e $\mathrm{Fe}_{2} \mathrm{O}_{3}, \mathrm{MgO}, \mathrm{TiO}_{2}$ e $\mathrm{CaO}$ e negativas entre $\mathrm{SM}_{2} \mathrm{~K}_{2} \mathrm{O}$ e $\mathrm{SiO}_{2}$ refletindo a tendência decrescente de $\mathrm{SM}$ com a diminuição do conteúdo modal de máficos e o aumento de quartzo e feldspato potássico, ou seja, paralelamente à diferenciação magmática. Os altos valores de SM, o conteúdo significativo de magnetita e a assembléia magmática magnetita-titanita-quartzo demonstram que o Granito Bannach evoluiu em condições relativamente oxidante provavelmente próximas daquelas dos tampões NNO.
\end{abstract}

Palavras-chave: suscetibilidade magnética, magnetita, ilmenita, granito tipo A oxidado, petrologia magnética.

\begin{abstract}
Magnetic petrology of the anorogenic Bannach granite, rio Maria granite-greenstone terrane, Pará. The Paleoproterozoic Bannach Granite is intrusive in Archean units of the Rio Maria Granite-Greenstone Terrane. The batholith is composed of three group of monzogranites rocks: a coarsegrained amphibole, biotite and sometimes clinopyroxene-bearing facies; a porphyritic facies with biotite; and leucogranitic fácies with varied textures. Magnetite, ilmenite, hematite, pyrite, chalcopyrite, sphalerite and goethite, are the opaque oxide minerals observed. Six textural types of ilmenite are distinguished: individual Ilmenite; internal and external composite Ilmenite; sandwich Ilmenite; patch Ilmenite; trellis Ilm. Texture features suggest that titanomagnetite and individual and composite ilmenite crystallized in early magmatic stage. The Ilmenite was destabilized and partially replaced by titanite still in the magmatic stage. During the subsolidus stage,titanomagnetite was transformed by oxidation-exsolution in to intergrowths of almost pure magnetite and ilmenite (sandwich, patch, and trellis ilmenite). Hematization of magnetite and oxidation of the pirite the latter with goethite formation occurred later at lower temperatures. Compared to the average of magnetic susceptibility (MS) for granites, the different facies of the Bannach pluton are characterized by high values of the MS. There is good correlation between MS and magmatic differentiation of the facies forming the batholith. MS decrease from the amphibole+biotite \pm clinopyroxene-bearing facies to the biotite porphyritic facies, attaining the lowest values in the leucogranites. The modal magnetite contents are high for granites. Opaque minerals, amphibole, total of mafic minerals and biotite modal contents show a positive correlations with MS. Positive correlations among $\mathrm{MS}$ and $\mathrm{Fe}_{2} \mathrm{O}_{3}, \mathrm{FeO}, \mathrm{MgO}$ and $\mathrm{TiO}_{2}$ contents and negative correlations between $\mathrm{MS}$ and $\mathrm{K}_{2} \mathrm{O}$ e $\mathrm{SiO}_{2}$ are consistent with the mentioned relationships between MS and modal mineral content. High MS, significant modal contents of magnetite, the high $\mathrm{Fe}_{2} \mathrm{O}_{3} / \mathrm{FeO}$ ratios and magmatic assemblage titanite $+\mathrm{Mt}+$ quartz demonstrate that the Bannach Granite evolved in relatively oxidizing conditions estimated as situated near those of the NNO buffer.
\end{abstract}

Keywords: Magnetic susceptibility, magnetite, ilmenite, oxidized A-type granite, magnetic petrology.

1 - Programa Pós Graduação em Geologia e Geoquímica. IG Univ. Federal do Pará, Belém, Pará. E-mails: ari@ufpa.br; fabricia@ufpa.br 2 - Faculdade Geologia, Instituto de Geociências, Univ. Federal do Pará, Bélem, Pará. Pesquisador CNPq. E-mail: robdal@ufpa.br 
INTRODUÇÃO O magmatismo anorogênico Proterozóico do Cráton Amazônico é um evento magmático dos mais expressivos. O Grupo de Pesquisa Petrologia de Granitóides (GPPG) tem desenvolvido diversos estudos sobre corpos anorogênicos de idade paleoproterozóica na região de Rio Maria. Esses trabalhos geraram um conhecimento expressivo sobre os maciços Jamon (Dall'Agnol 1980, Dall'Agnol et al. 1999), Musa (Gastal 1987), Marajoara (Rocha Jr, 2004), Redenção (Oliveira 2001, Oliveira et al. 2002) e Bannach (Almeida 2005). As similaridades em termos de idade e posicionamento estratigráfico, juntamente com as características geológicas, petrográficas e geoquímicas, permitiram que esses corpos fossem enquadrados dentro da Suíte Jamon (Dall'Agnol et al. 2005, Oliveira 2006). Estes maciços apresentam características subalcalinas e afinidades com os granitos tipo A (Loiselle \& Wones 1979, Collins et al. 1982, Pearce et al. 1984, Whalen et al. 1987, Eby 1992, King et al. 2001). Os granitos tipo A oxidados têm obtido crescente destaque na literatura, tendo grande relevância no Proterozóico Médio dos Estados Unidos (Anderson \& Morrison 2005), assim como na Amazônia (Dall'Agnol et al. 2005, Dall'Agnol \& Oliveira 2007).

O GPPG também desenvolve uma linha de pesquisa em petrologia magnética, voltada ao estudo da suscetibilidade magnética e dos minerais opacos, em particular em rochas graníticas do sudeste do Pará, no Cráton Amazônico. Tais estudos têm subsidiado a definição da tipologia e das condições de fugacidade de oxigênio ao longo da evolução dessas rochas (Magalhães \& Dall'Agnol 1992, Dall'Agnol et al 1997, Leite et al. 1997, Dall'Agnol et al 1999, Oliveira 2001, Oliveira et al. 2002, Figueiredo et al. 2003, Dall'Agnol et al. 2005, Nascimento 2006).

O presente trabalho foi realizado objetivando relacionar o comportamento magnético com os processos magmáticos e pós-magmáticos atuantes ao longo da evolução do Granito Bannach, bem como discutir as condições de fugacidade de oxigênio presentes nos diferentes estágios de cristalização do mesmo, utilizando-se para isso dos dados de suscetibilidade magnética e dos minerais óxidos de $\mathrm{Fe}$ e Ti, integrados com os de petrografia e geoquímica.

\section{ASPECTOS GEOLÓGICOS E PETROGRÁFI-}

COS A região de Bannach está localizada na porção oeste do Terreno Granito-Greenstone de Rio Maria (TGGRM; Fig. 1), borda sudeste do Cráton Amazônico, dentro da Província Mineral de Carajás. O TGGRM é formado por greenstone belts e granitóides de idade arqueana. Os greenstone belts do Supergrupo Andorinhas (Souza 1994) são a unidade mais antiga da região. É possível distinguir quatro grupos principais de granitóides arqueanos (Dall'Agnol et al. 2006, Leite 2001): 1) Granitóides da série tonalítica-trondhjemítica-granodiorítica (Tipo TTG) de idade entre 2.96 a $2.93 \mathrm{Ga}$, representados pelo Tonalito Arco Verde e Complexo Tonalítico Caracol; 2) Granitóides do tipo sanukitóide representados pelo Granodiorito Rio Maria e rochas máficas e intermediárias associadas; 3 ) granitóides TTG mais novos $(2,87 \mathrm{Ga})$ representados pelo Trondhjemito Mogno e Trondhjemito Água Fria e 4) Leucogranitos potássicos de afinidade cálcio-alcalina, caso dos granitos Xinguara, Mata Surrão, Guarantã e correlatos. As diversas unidades do TGGRM são cobertas por metassedimentos de idade arqueana do Grupo Rio Fresco e cortados por granitos anorogênicos paleoproterozóicos da Suíte Jamon.

Um dos corpos graníticos que integram esta suíte é o maciço Bannach. Ele é um batólito alongado na direção NNW-SSE (Fig. 2), intrusivo em unidades arqueanas, cuja foliação regional secciona claramente. Os contatos entre o corpo Bannach e suas encaixantes são em geral bruscos e bem expostos, sendo comuns na zona de contato, enclaves angulosos de rochas encaixantes englobados pelo Granito Bannach. Diversos granitos anorogênicos e diques associados da Província Mineral de Carajás possuem idade de 1,88 Ga (Machado et al. 1991, Barbosa et al. 1995, Dall'Agnol et al. 2005) e tal idade é também admitida para o Granito Bannach.

Embora tenha sido possível estender sem nenhuma dúvida os domínios do Granito Bannach a porção sul do corpo, as dificuldades de acesso não permitiram uma amostragem detalhada daquela área. Em razão disso, a distribuição de fácies só pôde ser definida nas porções central e norte do corpo.

As composições modais de 50 amostras das diferentes fácies do Granito Bannach foram plotadas nos diagramas Q-A-P e Q-A+P-M (Fig. 3), e a tabela 1 mostra a composição média das diferentes fácies do corpo (Almeida 2005, Almeida et al. 2006).

O maciço granítico Bannach é formado essencialmente por rochas monzograníticas isotrópicas, tendo sido distinguidos por Almeida et al. (2006) três grandes conjuntos petrográficos: a) fácies de granulação grossa portadoras de anfibólio + biotita \pm clinopiroxênio, representadas por: clinopiroxênio-biotita-anfibólio monzogranito equigranular grosso (CBAMzG), biotitaanfibólio monzogranito grosso (BAMzG) e anfibóliobiotita monzogranito grosso $(\mathrm{ABMzG})$; b) fácies portadora de biotita com textura porfirítica $(\mathrm{BMzP})$ e c) fácies leucograníticas, com termos grossos $(\mathrm{LMzG})$, médios (LMzM) e finos (LMzF).

As diferentes fácies possuem mineralogia similar, apresentando quartzo, microclina e plagioclásio como minerais essenciais; biotita, anfibólio e, mais raramente, clinopiroxênio como varietais; titanita, allanita, apatita e zircão como acessórios primários; sericitamuscovita, epidoto \pm fluorita como fases secundárias.

$\mathrm{O}$ diagrama $\mathrm{Q}-(\mathrm{A}+\mathrm{P})-\mathrm{M}$ permite separar as rochas com maior conteúdo de máficos daquelas hololeucocráticas. Os clinopiroxênio-biotita-anfibólio monzogranito equigranular grosso possuem os maiores conteúdos médios de minerais máficos $(\mathrm{M})(29,8 \%)$, sendo seguidos pelas fácies biotita-anfibólio monzogranito equigranular grosso $(11,3 \%)$ e anfibólio-biotita monzogranito equigranular grosso $(6,9 \%)$. A fácies biotita monzogranito porfirítico possui valor médio de $\mathrm{M}$ de 


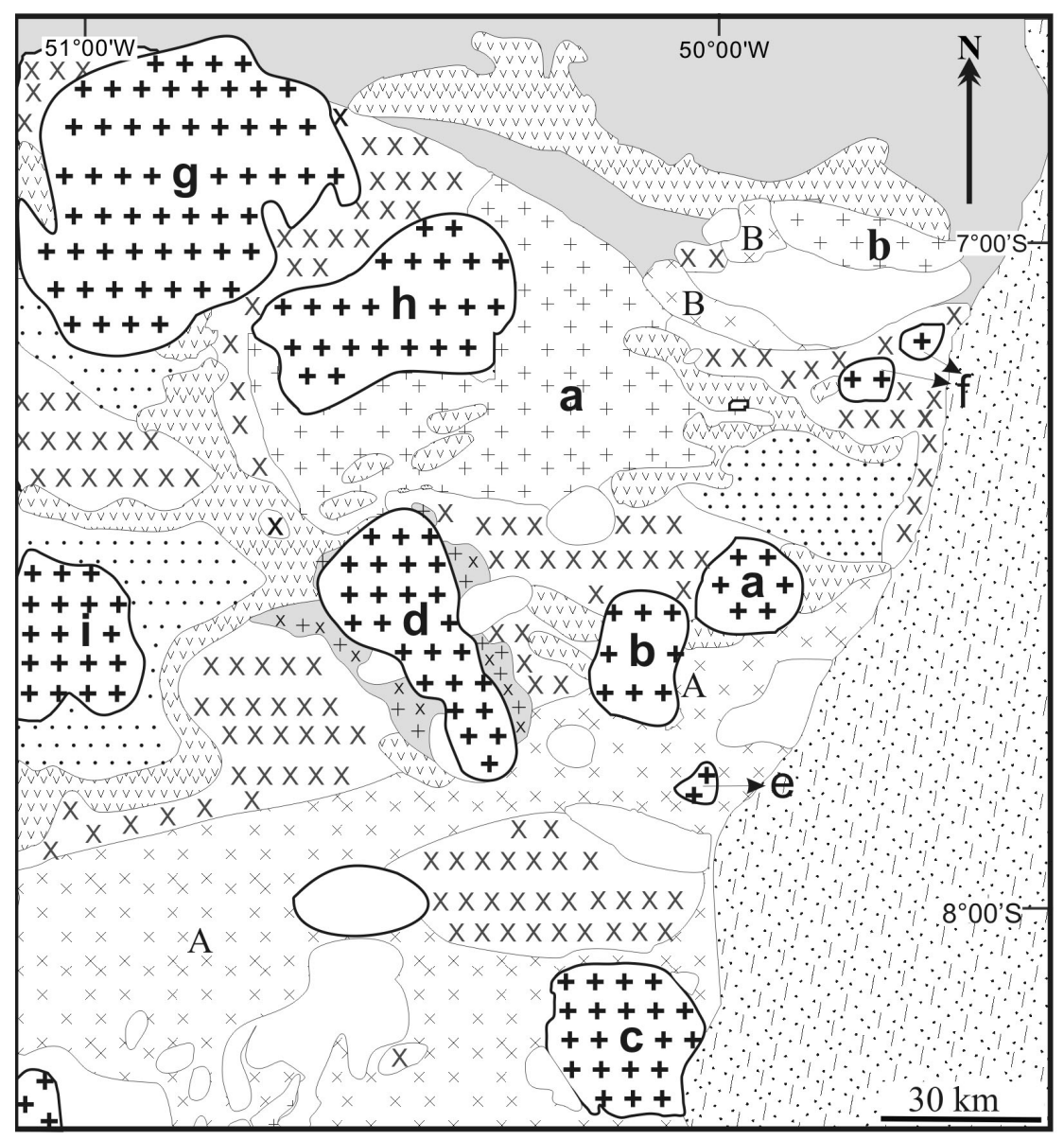

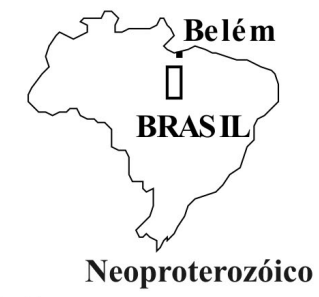

Cinturão Araguaia

\section{Paleoproterozóico}

$+\boldsymbol{+}+$ Granitos Anorogênicos a- Jamon; b- Musa; c- Redenção; d- Bannach; e- Marajoara; f- Manda Saia; g- Seringa; h- São João; i- Gradaús;

\section{Arqueano}



(b) Trondhjemito Água Fria

$x \times x$ Granodiorito Rio Maria

$+x+x$
$+x+$ Granitóides TTG indiferenciados

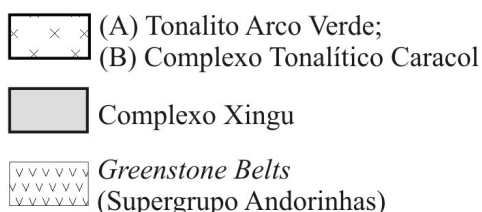

Figura 1 - Mapa geológico do Terreno Granito-Greenstone de Rio Maria reproduzido a partir de Oliveira 2001, modificado; Fontes: Huhn et al. 1988, Souza 1994, CPRM 2000, Althoff et al. 2000, Leite 2001.

6,7 e as fácies de leucogranitos possuem valores de $\mathrm{M}<$ $4 \%$. Isto revela que as referidas fácies derivam de líquidos cada vez mais pobres em constituintes ferromagnesianos, sugerindo, juntamente com os dados geoquímicos (Almeida 2005, Almeida et al. 2006), diferenciação magmática no sentido dos granitos com anfibólio para as fácies porfirítica e desta para os leucogranitos.

Os conteúdos modais de opacos são mais elevados nas fácies com clinopiroxênio $(3,8 \%)$, diminuindo no sentido daquelas com anfibólio $(1,9$ a $0,7 \%)$, e atingindo valores mínimos nas fácies leucograníticas $(0,1 \mathrm{a}$ $0,2 \%)$. Nos granitos porfiríticos os conteúdos são elevados $(1,4 \%)$, destoando da tendência dominante.

O anfibólio e a biotita são os principais ferromagnesianos, sendo que, a medida que diminui a quantidade total de ferromagnesianos das fácies, o anfibólio cede lugar gradativamente à biotita. Nas rochas mais leucocráticas, o anfibólio se torna muito escasso ou mesmo ausente, as proporções de biotita diminuem e as de clorita tornam-se mais expressivas.

Na figura 4 tem-se o mapa faciológico da porção norte, mostrando a distribuição e as composições modais médias, em termos de quartzo, fedspato potássico, plagioclásio e máficos, das diferentes fácies do Granito Bannach (Almeida 2005, Almeida et al. 2006). A distribuição espacial das fácies no interior do corpo sugere a existência de um zoneamento aproxima- damente concêntrico, com as fácies menos evoluídas, mais ricas em máficos e anfibólio, tendendo a ocupar a periferia e as mais evoluídas, correspondendo às fácies leucograníticas, as porções centrais do corpo.

MÉTODOS DE TRABALHO Com base no estudo petrográfico, foram selecionadas 83 amostras representativas das diferentes fácies do Granito Bannach para a avaliação do seu comportamento magnético. As medidas de suscetibilidade magnética (SM) foram efetuadas com o suscetibilímetro SI-1 (fabricado pela Saphire Instruments), pertencente ao Laboratório de Petrologia Magnética (LPM) do Centro de Geociências (CG) da Universidade Federal do Pará (UFPA). As amostras analisadas foram previamente serradas para a obtenção de superfícies planas, favoráveis para a utilização de um sensor retangular do tipo bobina plana de aproximadamente $2 \times 3 \mathrm{~cm}$, para a realização das medidas de SM. Os valores de SM obtidos com a bobina plana foram multiplicados por um fator de correção de 1,7 , determinado em estudos anteriores (Oliveira, et al. 2002, Figueiredo et al. 2003, Nascimento 2006). Este fator visa compensar diferenças observadas entre medidas com bobinas planas e cilindricas e foi determinado a partir de medidas comparativas em padrões. Os dados de SM foram tratados estatisticamente no programa Statistica versão 5.0, que permite a elaboração de gráfico de pro- 


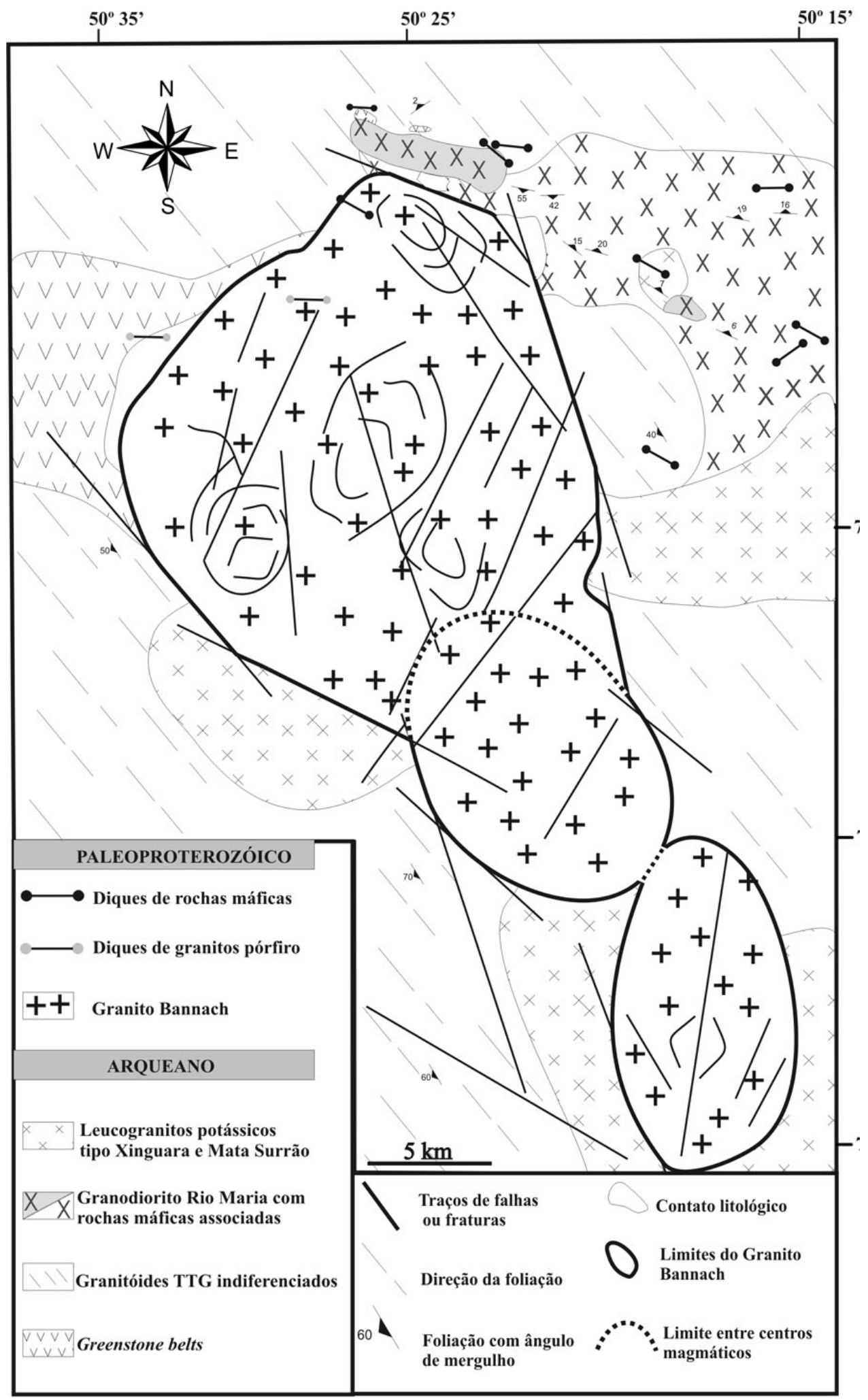

Figura 2 - Mapa geológico da região de ocorrência do Granito Bannnach (Modificado de Almeida 2005).

babilidade, histograma e polígono de freqüência, que serviram de base para as interpretações.

Foram selecionadas 16 amostras representativas das diferentes fácies do Granito Bannach para confecção de lâminas polidas, as quais foram analisadas em microscópio petrográfico, tanto em luz refletida como em luz transmitida, com o intuito de caracterizar as associações e as texturas dos minerais de óxidos de $\mathrm{Fe}$ e Ti e compreender o papel desses ao longo da evolução do maciço. Numa etapa posterior foram feitas observações em microscópio eletrônico de varredura (MEV) no Laboratório de Microscopia Eletrônica de Varredura (LA- 


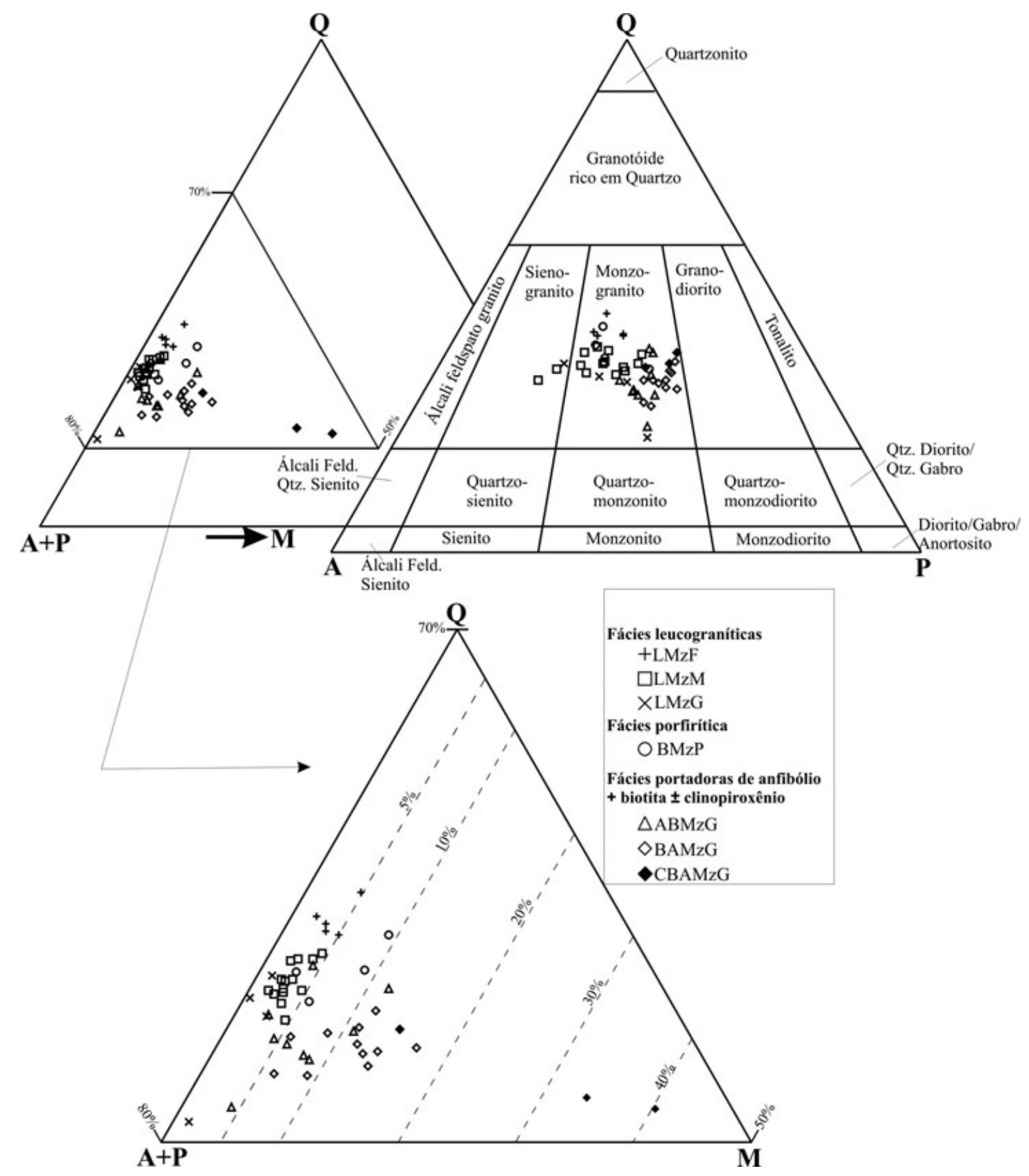

Figura 3 - Diagramas modais $Q-A-P($ Le Maitre 2002)) e Q-(A+P)-M para as variedades do Granito Bannach. Abreviações: $C B A M z G$ - clinopiroxênio-biotita-anfibólio monzogranito equigranular grosso; $B A M z G$ - biotita-anfibólio monzogranito equigranular grosso; $A B M z G$ - anfibólio-biotita monzogranito equigranular grosso; BMzP - biotita monzogranito porfirítico; $L M z G$-leucomonzogranito equigranular grosso; LMzM - leucomonzogranito equigranular médio; $L M z F$ - leucomonzogranito equigranular fino.

BMEV) do CG/UFPA, que complementaram o estudo petrográfico e permitiram uma melhor caracterização dos minerais opacos presentes nas rochas estudadas.

\section{RESULTADOS OBTIDOS}

Suscetibilidade Magnética (SM) A suscetibilidade magnética do Granito Bannach varia de $1,0780 \times 10^{-3} \mathrm{a}$ $72,7480 \times 10^{-3}$ (Tab. 2) com média de $9,2650 \times 10^{-3}$. Os dados de SM foram avaliados com base em histograma e polígono de freqüência (Figs. 5a e 5b, respectivamente), os quais mostraram que a distribuição das amostras desse corpo é claramente bimodal, observando-se dois picos distintos nos valores de $\log -2,75$ e $-2,10$ com grande parte das amostras (67\%) concentrando-se no intervalo entre log $-2,40$ e $-1,80$. A partir dos dados de $\mathrm{SM}$, foi possível a elaboração de gráfico de probabili- 
Tabela 1 - Composições modais médias das diferentes fácies do granito Bannach.

\begin{tabular}{|c|c|c|c|c|c|c|c|}
\hline \multirow[t]{2}{*}{ Fácies } & \multicolumn{3}{|c|}{$\begin{array}{l}\text { Fácies portadoras de anfibólio }+ \\
\text { biotita } \pm \text { clinopiroxênio }\end{array}$} & \multirow{2}{*}{$\begin{array}{c}\begin{array}{c}\text { Fácies } \\
\text { porfirítica }\end{array} \\
\mathrm{BMzP}\end{array}$} & \multicolumn{3}{|c|}{ Fácies Leucograníticas } \\
\hline & CBAMzG & BAMzG & $\mathrm{ABMzG}$ & & $\mathrm{LMzG}$ & LMzM & $\mathrm{LMzF}$ \\
\hline Mineral (\%) & $\{3\}$ & $\{11\}$ & $\{9\}$ & $\{4\}$ & $\{4\}$ & $\{14\}$ & $\{5\}$ \\
\hline Quartzo & 26,0 & 29,0 & 30,4 & 36,6 & 31,0 & 35,1 & 41,5 \\
\hline K-feldspato & 17,8 & 24,2 & 28,7 & 30,1 & 36,3 & 34,6 & 29,9 \\
\hline Plagioclásio & 26,4 & 34,5 & 33,6 & 26,1 & 30,8 & 25,7 & 24,3 \\
\hline Biotita & 7,5 & 2,7 & 3,8 & 2,9 & 0,3 & 1,8 & 1,2 \\
\hline Anfibólio & 16,4 & 5,3 & 1,4 & - & 0,2 & - & - \\
\hline Clinopiroxênio & 0,9 & 0,4 & 0,1 & - & - & - & - \\
\hline Opacos & 3,8 & 1,9 & 0,7 & 1,4 & 0,2 & 0,1 & $<0,1$ \\
\hline Titanita & 0,4 & 0,1 & 0,2 & 0,6 & - & - & - \\
\hline Allanita & 0,2 & 0,2 & 0,3 & 0,2 & - & - & - \\
\hline Clorita & 0,1 & 0,3 & 0,3 & 1,5 & 0,7 & 1,1 & 2,5 \\
\hline Muscovita & - & - & 0,1 & - & - & 0,4 & 0,1 \\
\hline Fluorita & - & 0,2 & - & 0,1 & - & 0,1 & - \\
\hline Albita intergran. & - & 1,0 & 0,4 & 0,5 & 0,5 & 1,0 & 0,5 \\
\hline Acessórios (Ap+Zr) & 0,5 & 0,1 & 0,1 & $<0,1$ & - & - & $<0,1$ \\
\hline Félsicos & 70,2 & 88,7 & 93,1 & 93,3 & 98,5 & 96,4 & 96,3 \\
\hline Máficos & 29,8 & 11,3 & 6,9 & 6,7 & 1,5 & 3,6 & 3,7 \\
\hline $\mathrm{A}+\mathrm{P}$ & 44,2 & 58,7 & 62,3 & 56,1 & 67,0 & 60,3 & 54,3 \\
\hline $\mathrm{Q}+\mathrm{A}$ & 43,8 & 53,2 & 59,1 & 66,7 & 67,3 & 69,6 & 71,4 \\
\hline Biot + Clorita & 7,6 & 3,0 & 4,0 & 4,4 & 1,3 & 2,9 & 3,7 \\
\hline Anf/Biot & 2,2 & 2,0 & 0,4 & 0,0 & 0,6 & 0,0 & 0,0 \\
\hline \multicolumn{8}{|l|}{ A $100 \%$} \\
\hline Quartzo & 37,1 & 33,1 & 32,8 & 39,5 & 31,6 & 36,8 & 43,3 \\
\hline K-feldspato & 25,0 & 27,6 & 30,9 & 32,4 & 37,0 & 36,2 & 31,3 \\
\hline Plagioclásio & 37,8 & 39,3 & 36,2 & 28,1 & 31,4 & 27,0 & 25,4 \\
\hline $\mathrm{Pl} / \mathrm{Fk}$ & 1,5 & 1,4 & 1,2 & 0,9 & 0,8 & 0,7 & 0,8 \\
\hline
\end{tabular}

dade normal (Fig. 5c), que possibilitou a caracterização de cinco populações denominadas de A, B, C, D, E, as quais foram definidas a partir de diferentes segmentos de reta que cobrem intervalos distintos de SM, partindo dos menores para os maiores valores de SM.

RELAÇÕES ENTRE SM E FÁCIES Observa-se uma boa correlação entre os dados de SM e a provável evolução magmática do Granito Bannach. O histograma de freqüência (Fig. 5a) mostra que as fácies portadoras de anfibólio + biotita \pm clinopiroxênio (CBAMzG, BA$\mathrm{MzG}$ e $\mathrm{ABMzG}$ ), as quais são mais ricas em máficos, apresentam os valores mais elevados de SM. As demais fácies tendem a tornar-se gradualmente menos magnéticas, à medida que diminuem os conteúdos modais de máficos. Os valores mais baixos de SM são apresentados pelas fácies de leucogranitos por serem mais pobres em máficos e, provavelmente, derivadas de líquidos mais evoluídos no processo magmático. Os dados magnéticos das diferentes fácies do Granito Bannach podem ser resumidos da seguinte forma:
1 - A população A, responsável pelo pico definido pelas rochas com menor SM, formada por $30 \%$ do total das amostras, apresenta os menores valores de SM do conjunto estudado (Tab. 2), com variação entre 1,0780 $\times 10^{-3}$ e $3,5813 \times 10^{-3}$ e valor médio de $2,3296 \times 10^{-3}$. É formada principalmente pelos leucogranitos. Além das fácies citadas estão presentes nessa população, três amostras da fácies biotita monzogranito porfirítico que apresentam valores de SM inferiores aos geralmente fornecidos por esta fácies, o que indica um conteúdo modal comparativamente mais reduzido de minerais opacos e magnetita nestas amostras.

2 - A população B engloba as amostras com valores intermediários de $\mathrm{SM}$ do corpo, os quais variam de $4,4135 \times 10^{-3}$ a $8,0512 \times 10^{-3}$ com média de $6,2323 \times 10^{-3}$, reunindo $35 \%$ da amostragem total. Este grupo é bastante heterogêneo em termos de litotipos, sendo formado pelas fácies porfirítica e anfibólio-biotita monzogranito, que apresentam a biotita como o principal mineral máfico, e, subordinadamente, pelos leucogranitos.

3 - A população $C$ apresenta uma variação de SM um 


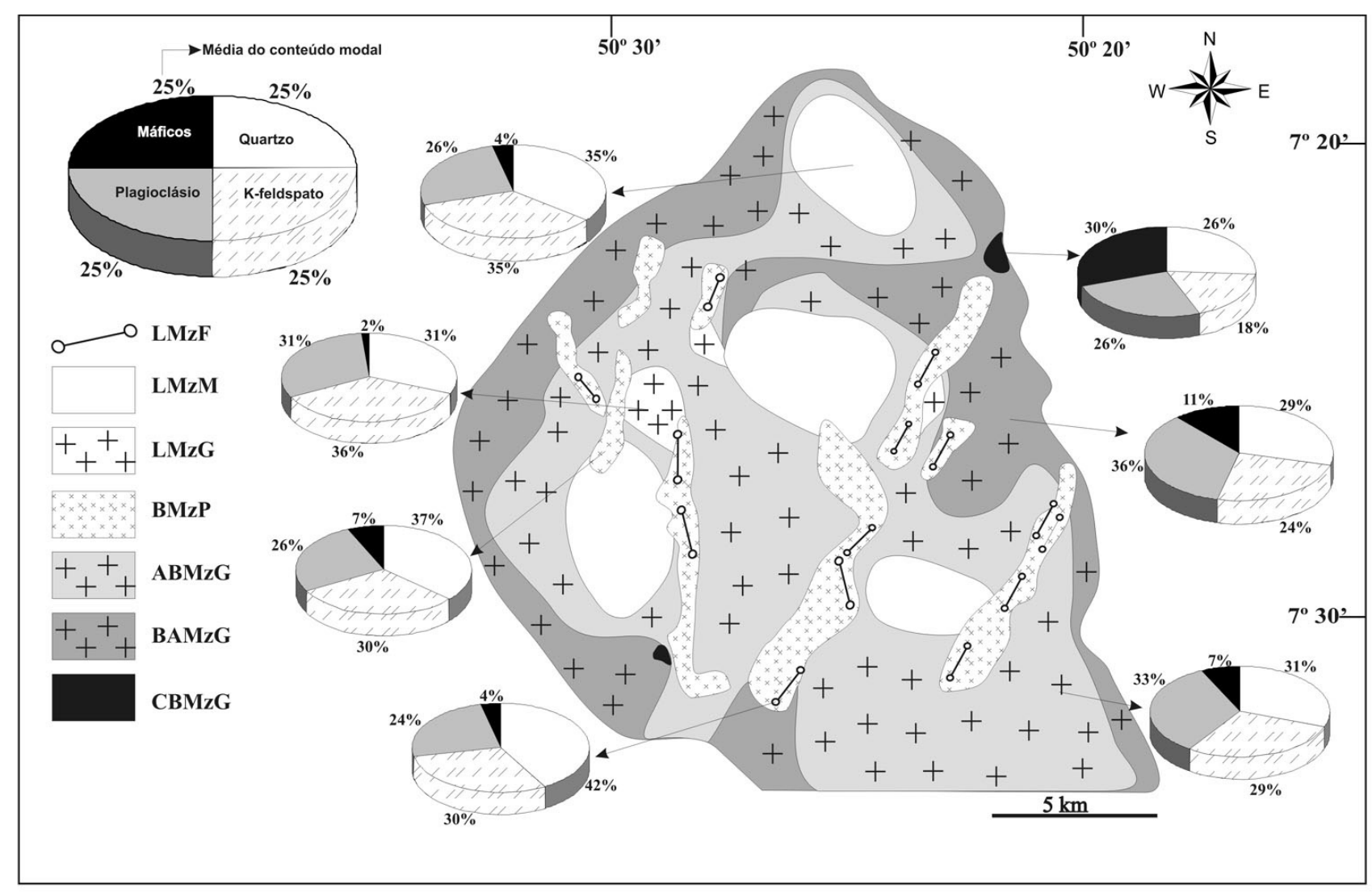

Figura 4 - Mapa faciológico da porção norte do Granito Bannach, mostrando a distribuição das diferentes fácies e as suas composições modais médias. Abreviações conforme Figura 3.

pouco mais ampla, entre $8,159 \times 10^{-3} \mathrm{e} 15,754 \times 10^{-3}$ e média de $11,956 \times 10^{-3}$. Corresponde a $26,5 \%$ dos dados e é constituída principalmente por biotita-anfibólio monzogranito e, subordinadamente, pela fácies porfirítica e anfibólio-biotita monzogranito, e duas amostras da fácies leucomonzogranito médio.

4 - A população D mostra valor médio de SM de $23,034 \times 10^{-3}$ e compreende valores de $18,637 \times 10^{-3}$ a $27,432 \times 10^{-3}$. Engloba 4,8\% das amostras estudadas e é formada por fácies muito variadas, ora com dominância de biotita, ora de anfibólio \pm clinopiroxênio.

5 - A população E reúne apenas $3,6 \%$ dos dados, fornecidos pelas amostras mais magnéticas do Granito Bannach, com valores de SM que se situam no intervalo de $48,705 \times 10^{-3}$ a $72,748 \times 10^{-3}$, com média de $60,726 \times 10^{-3}$. Ela é composta unicamente pelas fácies ricas em anfibólio \pm clinopiroxênio e que apresentam maior conteúdo de minerais máficos.

O mapa de contorno de SM (Fig. 6a) permite visualizar vários domínios magnéticos no corpo Bannach, notando-se que os valores mais elevados de SM estão situados nas bordas do corpo (tons cinza escuro), ao passo que aqueles menores tendem a se dispor na porção central do mesmo (branco). Um perfil NE-SW (Fig. 6b) revela o zoneamento aproximadamente simétrico em termos de SM do Granito Bannach, já que na periferia do corpo os valores de SM são elevados e muito próximos, diminuindo acentuadamente em direção ao centro do maciço. Isso é coerente com a distribuição faciológica do corpo, uma vez que os domínios de mais alta SM (borda do corpo) são espacialmente coincidentes com as fácies portadoras de anfibólio+biotita \pm clin opiroxênio (CBAMZG, BAMzG e ABMzG) e os de mais baixa SM com os leucogranitos (principalmente os LMzG e LMzM). Portanto, há, de modo geral, uma forte tendência à diminuição dos valores de SM da borda para o centro do corpo, refletindo as relações entre SM e a distribuição de fácies no corpo.

RELAÇÕES ENTRE SM E COMPOSIÇÃO MO$D A L$ Excetuando os leucrogranitos, os quais perfazem cerca de $40 \%$ das amostras estudadas e apresentam valores modais médios de opacos igual ou inferiores a $0,2 \%$, as diferentes fácies do Granito Bannach apresentam valores modais médios bastante expressivos de minerais opacos (3,8 a 0,7\%; Tab. 1).

Somente nas fácies em que o anfibólio é o máfico dominante [(clinopiroxênio)-biotita-anfibóliomonzogranito] e em algumas amostras de biotita monzogranito porfirítico, os valores modais de opacos são superiores a $1,5 \%$. Elas representam cerca de $20 \%$ das amostras estudadas. Em geral nota-se uma nítida diminuição nos conteúdos de minerais opacos no sentido das fácies mais ricas em máficos para as hololeucocráticas e existe uma nítida correlação positiva entre os valores de SM e o conteúdo modal de minerais opacos (Fig. 7a).

As afinidades mineralógicas entre determinadas 
Tabela 2 - Dados de suscetibilidade magnética (SM) do Granito Bannach. Siglas conforme tabela 1. $K(S I v)=$ Valor médio de SM em volume de cada amostra no Sistema Internacional .

\begin{tabular}{|c|c|c|c|c|c|}
\hline População & $\mathrm{N}^{\circ}$ & Amostras & $\mathrm{K}(\mathrm{SIV})\left(\mathrm{x} 10^{-3}\right)$ & Log K (SIv) & Fácies \\
\hline \multirow{3}{*}{ "E" } & 1 & ADR-136I & 72,748 & $-1,13817$ & CBAMzG \\
\hline & 2 & ADR-136H & 53,166 & $-1,27436$ & CBAMzG \\
\hline & 3 & ADR-218 & 48,705 & $-1,31242$ & BAMzG \\
\hline \multirow{4}{*}{ “D” } & 4 & ADR-237D & 27,432 & $-1,56174$ & CBAMzG \\
\hline & 5 & ADR-40A & 23,23 & $-1,63395$ & $\mathrm{BMzP}$ \\
\hline & 6 & ADR-230B & 22,746 & $-1,64309$ & $\mathrm{BMzP}$ \\
\hline & 7 & ADR-110 & 18,637 & $-1,72962$ & $\mathrm{ABMzG}$ \\
\hline \multirow{22}{*}{ "C" } & 8 & ADR-45B & 15,754 & $-1,8026$ & $\mathrm{BMzP}$ \\
\hline & 9 & ADR-74E & 15,492 & $-1,80988$ & BAMzG \\
\hline & 10 & ADR-151A & 14,435 & $-1,84057$ & $\mathrm{BMzP}$ \\
\hline & 11 & ADR-15A & 14,267 & $-1,84566$ & LMzM \\
\hline & 12 & ADR-14E & 13,387 & $-1,87331$ & $\mathrm{BMzP}$ \\
\hline & 13 & ADR-53A & 13,23 & $-1,87844$ & BAMzG \\
\hline & 14 & ADR-60B & 12,661 & $-1,89753$ & BAMzG \\
\hline & 15 & ADR-21B & 12,615 & $-1,89911$ & BAMzG \\
\hline & 16 & ADR-226 & 12,509 & $-1,90277$ & $\mathrm{ABMzG}$ \\
\hline & 17 & ADR-237A & 12,061 & $-1,91859$ & BAMzG \\
\hline & 18 & ADR-23A & 12,021 & $-1,92005$ & BAMzG \\
\hline & 19 & ADR-21A & 11,519 & $-1,93858$ & BAMzG \\
\hline & 20 & ADR-26A & 11,433 & $-1,94183$ & BAMzG \\
\hline & 21 & ADR-67A & 11,394 & $-1,94332$ & BAMzG \\
\hline & 22 & ADR-136C & 10,938 & $-1,96106$ & BAMzG \\
\hline & 23 & ADR-55H & 10,341 & $-1,98543$ & BAMzG \\
\hline & 24 & ADR-14B & 10,267 & $-1,98855$ & $\mathrm{BMzP}$ \\
\hline & 25 & ADR-78A & 10,075 & $-1,99675$ & BAMzG \\
\hline & 26 & ADR-27A & 9,7284 & $-2,01195$ & BAMzG \\
\hline & 27 & ADR-55C & 9,265 & $-2,03315$ & $\mathrm{ABMzG}$ \\
\hline & 28 & ADR-9A & 9,2327 & $-2,03467$ & BAMzG \\
\hline & 29 & ADR-63A & 8,1593 & $-2,08834$ & LMzM \\
\hline \multirow{13}{*}{ "B” } & 30 & ADR-136A & 8,0512 & $-2,09413$ & $\mathrm{ABMzG}$ \\
\hline & 31 & ADR-234 & 7,8311 & $-2,10617$ & $\mathrm{ABMzG}$ \\
\hline & 32 & ADR-58A & 7,7936 & $-2,10826$ & $\mathrm{ABMzG}$ \\
\hline & 33 & ADR-64A & 7,6653 & $-2,11547$ & $\mathrm{ABMzG}$ \\
\hline & 34 & ADR-241 & 7,6279 & $-2,11759$ & $\mathrm{ABMzG}$ \\
\hline & 35 & ADR-41A & 7,3547 & $-2,13343$ & $\mathrm{BMzP}$ \\
\hline & 36 & ADR-30D & 7,3899 & $-2,13136$ & $\mathrm{BMzP}$ \\
\hline & 37 & ADR-98A & 7,2669 & $-2,13865$ & $\mathrm{ABMzG}$ \\
\hline & 38 & ADR-32B & 7,1468 & $-2,14588$ & $\mathrm{LMzG}$ \\
\hline & 39 & ADR-100A & 7,0464 & $-2,15203$ & $\mathrm{ABMzG}$ \\
\hline & 40 & ADR-35A & 7,0201 & $-2,15365$ & $\mathrm{LMzF}$ \\
\hline & 41 & ADR-41B & 6,9188 & $-2,15996$ & $\mathrm{ABMzG}$ \\
\hline & 42 & ADR-31B & 6,8578 & $-2,16381$ & $\mathrm{ABMzG}$ \\
\hline
\end{tabular}

fácies, imprecisões nas medidas de SM e de conteúdo modal, podem justificar as superimposições observadas entre as diferentes fácies. Além disso, a presença de minerais opacos diferentes da magnetita, também pode explicar variações nos valores de SM em amostras com conteúdos de opacos semelhantes. Outro ponto a considerar, é a influência da variação no tamanho dos cristais de magnetita, que poderia provocar oscilações de SM 



Figura 5 - (a) Histograma de freqüencia mostrando a distribuição das principais associações de fácies do Granito Bannach. As barras indicam os intervalos de SM das cinco populações, bem como das diversas fácies. Siglas conforme a figura 3; (b) Polígono de freqüencia e (c) Gráfico de probabilidade referentes aos dados de SM.

em amostras com a mesma quantidade deste mineral (Clark 1999). Embora ocorram superposições entre as fácies, de modo geral observa-se uma separação entre as rochas portadoras de anfibólio + biotita \pm clinopiroxênio daquelas hololeucocráticas. As primeiras deslocam-se para os maiores valores de SM (direita do diagrama), ao passo que as rochas hololeucocráticas ocupam a parte esquerda do diagrama, apresentando baixos valores de SM. Isso reflete o fato de que, de modo geral os minerais opacos, entre eles se destacando a magnetita, são fases precoces na cristalização e associam-se preferencialmente com anfibólio e biotita ao longo da evolução do corpo.

Também se verifica uma clara correlação positiva entre os valores de $\mathrm{SM}$ e as proporções modais de máficos (Fig. 7b). As fácies mais ricas em máficos, provavelmente menos evoluídas no processo de diferenciação magmática, possuem valores mais elevados de SM. Isso indica que, quanto maior for a quantidade modal dos ferromagnesianos, provavelmente maiores serão as proporções modais de opacos e também de magnetita e, conseqüentemente, maior será o valor de SM.

Os valores de SM apresentam uma correlação positiva em relação ao conteúdo modal de anfibólio (Fig. 7c), confirmando a tendência geral da diminuição dos valores de SM no sentido das amostras mais leucrocráticas e potencialmente mais tardias. A formação dos minerais opacos e da magnetita, assim como a do anfibólio se dá nos estágios iniciais de cristalização, justificando, portanto, os maiores valores de SM das fácies precoces, mais ricas nestes minerais.

Os valores de SM e conteúdo modal de biotita (Fig. 7d) apresentam, de modo geral uma correlação positiva, para as fácies mais ricas em máficos (fácies com anfibólio e porfirítica) e negativa para os leucogranitos. Da mesma forma que ocorre com as razões microclina/plagioclásio, o somatório dos conteúdos modais de quartzo e feldspato potássico apresenta uma correlação negativa com a SM (Fig. 7e), sugerindo que a evolução magmática se daria no sentido das fácies mais ricas em anfibólio para o biotita monzogranito e deste para os leucogranitos, sendo acompanhada por decréscimo gradual nos valores de SM.

RELAÇÕES ENTRE SM E COMPOSIÇÃO QUÍMI$C A$ As composições químicas das amostras de diferentes variedades do Granito Bannach foram obtidas por Almeida (2005) e suas composições médias constam de Almeida et al. (2006).

As rochas do Granito Bannach mostram uma correlação positiva entre os valores de $\mathrm{SM}$ e aqueles dos óxidos $\mathrm{Fe}_{2} \mathrm{O}_{3}$ t, $\mathrm{FeO}, \mathrm{MgO}, \mathrm{CaO}$ (Figs. 8a,b,c e d). Estas correlaçỗes são bem marcadas, ficando clara a relação entre as variações de SM e as dos conteúdos de óxidos concentrados nos minerais máficos, confirmando o indicado pelos dados modais. Também neste caso ocorre alguma superposição entre os pontos representativos das diferentes fácies, com exceção dos monzogranitos com clinopiroxênio, que possuem sempre conteúdos destes óxidos e SM bem superiores aos das demais fácies. As fácies que são mais ricas nos óxidos acima citados são mais precoces e possuem SM mais elevada do que as fácies mais evoluídas (biotita monzogranito 
Tabela 2 (cont.) - Dados de suscetibilidade magnética (SM) do Granito Bannach. Siglas conforme tabela 1. K (SIv)=Valor médio de SM em volume de cada amostra no Sistema Internacional.

\begin{tabular}{|c|c|c|c|c|c|}
\hline População & $\mathrm{N}^{\circ}$ & Amostras & $\mathrm{K}(\mathrm{SIV})\left(\mathrm{x} 10^{-3}\right)$ & Log K (SIv) & Fácies \\
\hline \multirow{16}{*}{ "B" } & 43 & ADR-55A & 6,8051 & $-2,16716$ & ABMzG \\
\hline & 44 & ADR-212 & 6,5956 & $-2,18074$ & $\mathrm{ABMzG}$ \\
\hline & 45 & ADR-54A & 6,2752 & $-2,20237$ & LMzM \\
\hline & 46 & ADR-220B & 6,275 & $-2,20238$ & $\mathrm{BMzP}$ \\
\hline & 47 & ADR-38A & 6,1417 & $-2,2117$ & $\mathrm{BMzP}$ \\
\hline & 48 & ADR-55J & 5,9204 & $-2,22764$ & LMzF \\
\hline & 49 & ADR-197C & 5,8912 & $-2,22979$ & $\mathrm{BMzP}$ \\
\hline & 50 & ADR-230C & 5,6434 & $-2,24845$ & $\mathrm{BMzP}$ \\
\hline & 51 & ADR-10A & 5,4456 & $-2,26395$ & LMzM \\
\hline & 52 & ADR-111 & 5,3476 & $-2,27184$ & $\mathrm{BMzP}$ \\
\hline & 53 & ADR-55B & 5,2953 & $-2,2761$ & $\mathrm{ABMzG}$ \\
\hline & 54 & ADR-41D & 5,274 & $-2,27785$ & $\mathrm{LMzF}$ \\
\hline & 55 & ADR-68C & 5,2237 & $-2,28201$ & $\mathrm{ABMzG}$ \\
\hline & 56 & ADR-31A & 5,0247 & $-2,29629$ & $\mathrm{LMzG}$ \\
\hline & 57 & ADR-28B & 4,4412 & $-2,35249$ & $\mathrm{LMzG}$ \\
\hline & 58 & ADR-59A & 4,4135 & $-2,35521$ & $\mathrm{BMzP}$ \\
\hline \multirow{25}{*}{ "A" } & 59 & ADR-18A & 3,5813 & $-2,44594$ & LMzG \\
\hline & 60 & ADR-35B & 3,553 & $-2,4494$ & $\mathrm{LMzF}$ \\
\hline & 61 & ADR-27D & 3,5043 & $-2,45539$ & LMzG \\
\hline & 62 & ADR-68B & 3,3194 & $-2,47893$ & LMzM \\
\hline & 63 & ADR-23B & 3,2039 & $-2,4943$ & LMzM \\
\hline & 64 & ADR-30C & 2,5692 & $-2,5902$ & LMzG \\
\hline & 65 & ADR-59C & 2,5253 & $-2,59767$ & LMzF \\
\hline & 66 & ADR-34A & 2,4417 & $-2,6123$ & LMzG \\
\hline & 67 & ADR-19C & 2,4043 & $-2,619$ & LMzM \\
\hline & 68 & ADR-140 & 2,3055 & $-2,63723$ & LMzM \\
\hline & 69 & ADR-61A & 2,2414 & $-2,64947$ & $\mathrm{BMzP}$ \\
\hline & 70 & ADR-69A & 2,1692 & $-2,6637$ & LMzF \\
\hline & 71 & ADR-52A & 2,0163 & $-2,69542$ & LMzM \\
\hline & 72 & ADR-46A & 2,009 & $-2,69702$ & LMzM \\
\hline & 73 & ADR-194B & 1,9592 & $-2,70792$ & LMzM \\
\hline & 74 & ADR-119 & 1,9491 & $-2,70092$ & LMzM \\
\hline & 75 & ADR-45A & 1,938 & $-2,71264$ & $\mathrm{BMzP}$ \\
\hline & 76 & ADR-12A & 1,9221 & $-2,7162$ & LMzM \\
\hline & 77 & ADR-27C & 1,8431 & $-2,73444$ & LMzM \\
\hline & 78 & ADR-154 & 1,6451 & $-2,78379$ & LMzM \\
\hline & 79 & ADR-103A & 1,4675 & $-2,83341$ & LMzM \\
\hline & 80 & ADR-130A & 1,2745 & $-2,89466$ & LMzM \\
\hline & 81 & ADR-205 & 1,1911 & $-2,92402$ & LMzM \\
\hline & 82 & ADR-37A & 1,0888 & $-2,96305$ & $\mathrm{LMzF}$ \\
\hline & 83 & ADR-143 & 1,078 & $-2,96736$ & LMzM \\
\hline
\end{tabular}

porfirítico e leucogranitos). Esta interpretação é reforçada pela forte correlação negativa observada entre os valores de $\mathrm{SM}$ e os óxidos $\mathrm{SiO}_{2}$ e $\mathrm{K}_{2} \mathrm{O}$ (Figs. 8e,f) que crescem durante o fracionamento. Ela mostra que o decréscimo de SM deu-se paralelamente à diferenciação magmática do Granito Bannach. 


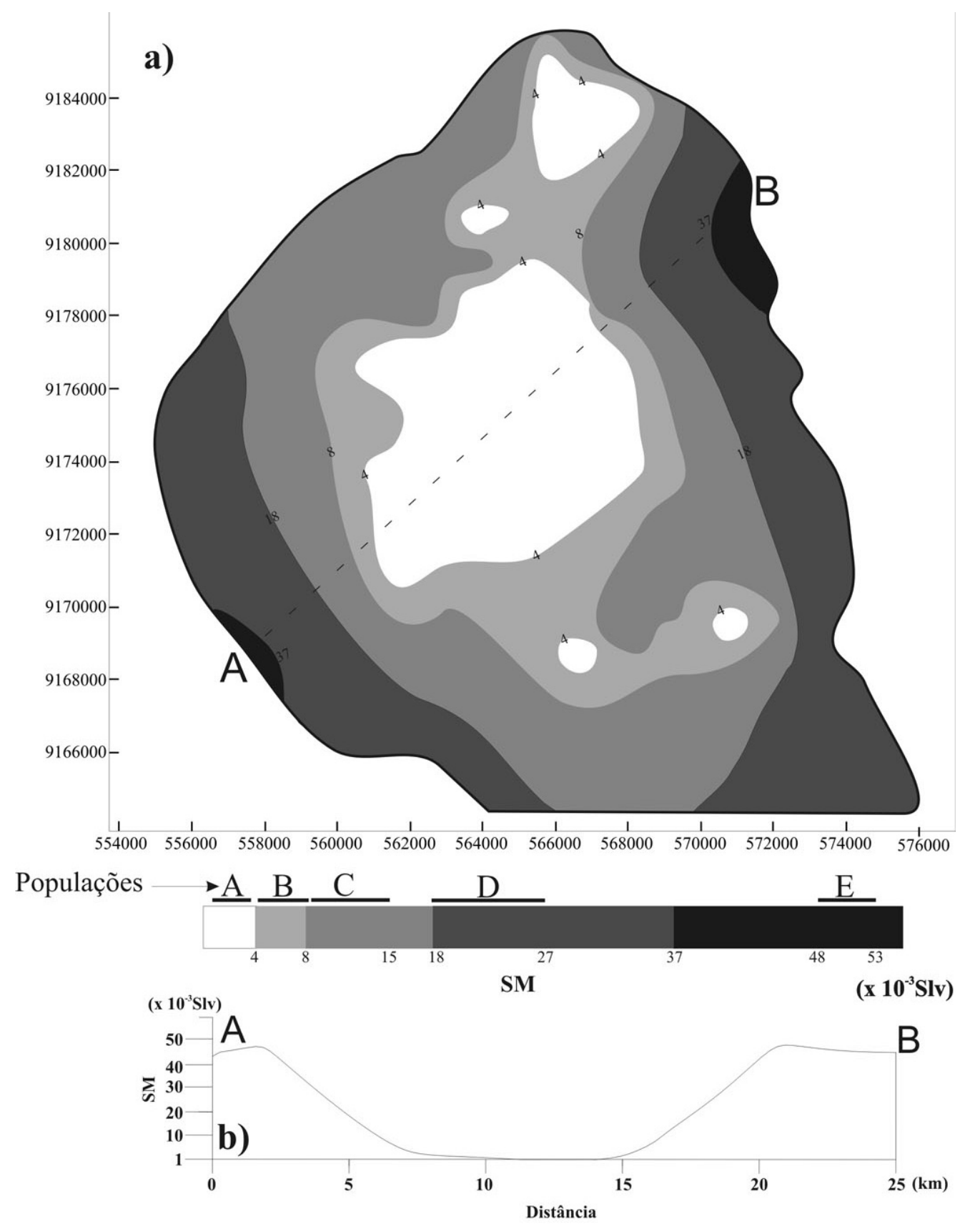

Figura 6 - a) Mapa de contorno de suscetibilidade magnética (SM) do Granito Bannach. Notar que os maiores valores de SM encontram-se nas bordas do corpo, onde ocorrem as fácies menos evoluídas, mais ricas em máficos. Ao contrário, na porção central do batólito, na área de ocorrência dos leucogranitos, encontram-se os menores valores de SM; b) Perfil NE-SW (BA) mostrando as variações de SM das diversas fácies do Granito Bannach.

Minerais óxidos de Fe e Ti Os minerais opacos presentes no Granito Bannach são magnetita (Mt), Ilmenita (Ilm), hematita (Ht), geralmente na forma de martita, e, ocasionalmente, pirita (Py), calcopirita (Cpy) e esfalerita. As diferentes fácies do corpo Bannach apresentam muitas analogias mineralógicas em termos dos minerais opacos, porém elas mostram variações marcantes nos seus conteúdos modais e, principalmente, nas feições texturais dos mesmos. Estes minerais geralmente estão associados aos minerais ferromagnesianos, acompanhando mais comumente anfibólio, biotita e minerais acessórios precoces na cristalização (ver Almeida et al. 2006).

Magnetita A magnetita ocorre dominantemente como cristais hipidiomórficos e, mais raramente, xenomórficos associados aos minerais ferromagnesianos (Fig. 9a). Mostra contatos regulares com estes e associa-se com ilmenita. Observa-se, ainda, magnetita bordejada por titanita com contatos regulares ou levemente reentrantes, sugerindo, no último caso, a existência de interação entre os dois minerais. Por vezes, os cristais 

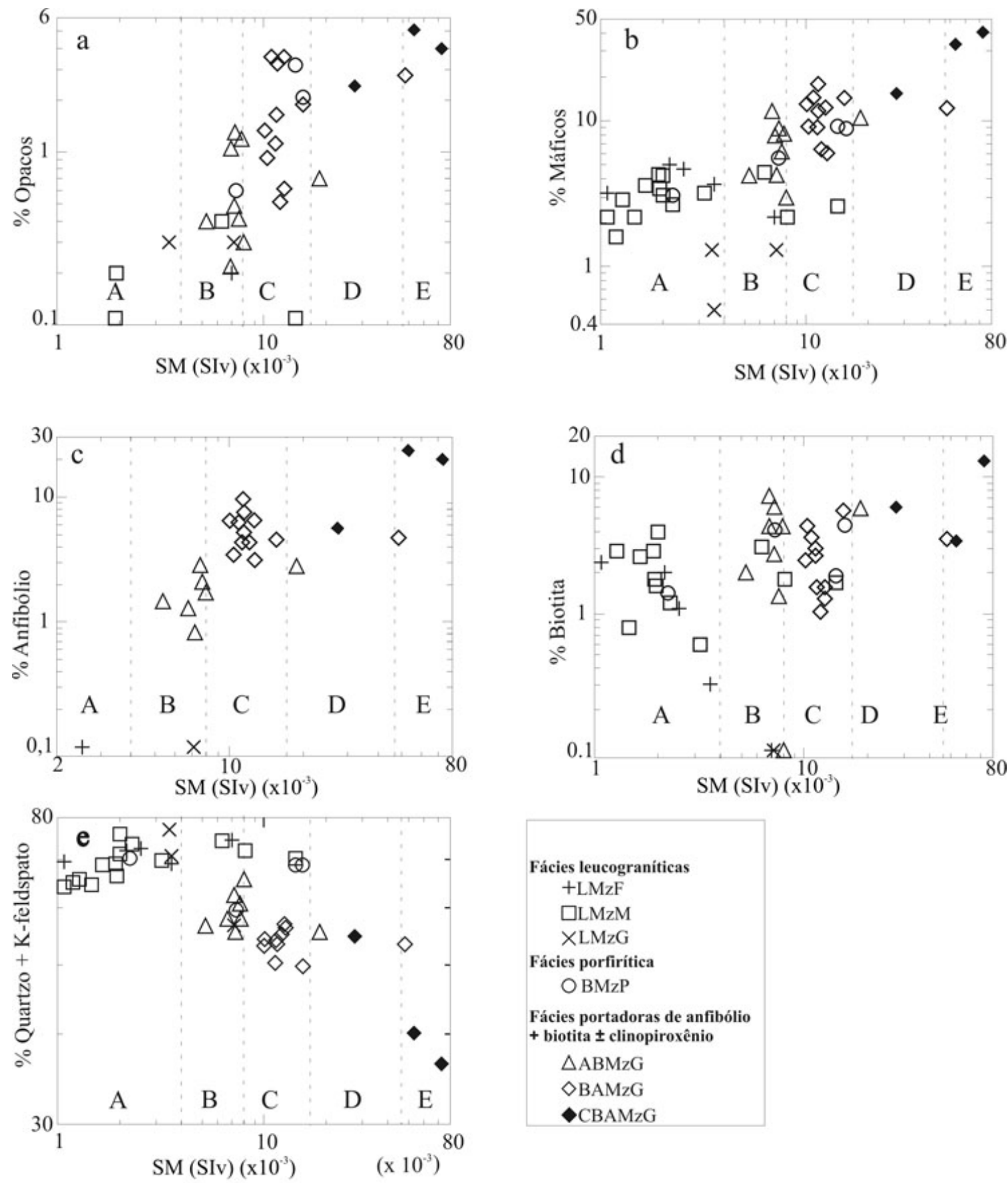

Figura 7 - Diagramas mostrando nas diferentes fácies do Granito Bannach, as relações entre o comportamento dos valores de suscetibilidade magnética (SM) e os conteúdos modais de: a) Opacos, b) Máficos, c) Anfibólio, d) Biotita, e) Quartzo+K-feldspato. A, B, C, D e E-Populações de $S M$.

de magnetita acham-se inclusos em minerais félsicos. Nas fácies portadoras de anfibólio + biotita \pm clinopiroxênio e nos monzogranitos porfiríticos, os cristais de magnetita são mais abundantes e mostram incipiente martitização nas suas bordas. O conteúdo modal de magnetita nos leucogranitos é bastante reduzido e seus cristais mostram-se mais oxidados (Fig. 9b), comparativamente às fácies precedentes.

Análises semi-quantitativas obtidas por meio de EDS em microscópio eletrônico de varredura (MEV), demonstram que os cristais de magnetita possuem baixos teores de titânio (Fig. 10a). Isto juntamente com sua associação com diversos tipos texturais de ilmenita, sugere que a associação magnetita-ilmenita foi derivada de titanomagnetita (TMt) (solução sólida entre ulvoespinélio e magnetita). Este processo, que leva à transformação da titanomagnetita primária em intercrescimentos de magnetita com ilmenita, ocorre através de uma série complexa de reações de reequilíbrio durante o resfriamento e não envolve apenas exsolução, mas também oxidação de modo a transformar o componente ulvoespinélio da titanomagnetita em ilmenita. Daí ser designado como processo de oxi-exsolução (Buddington \& Lindsley 1964, Dall'Agnol et al. 1997, 

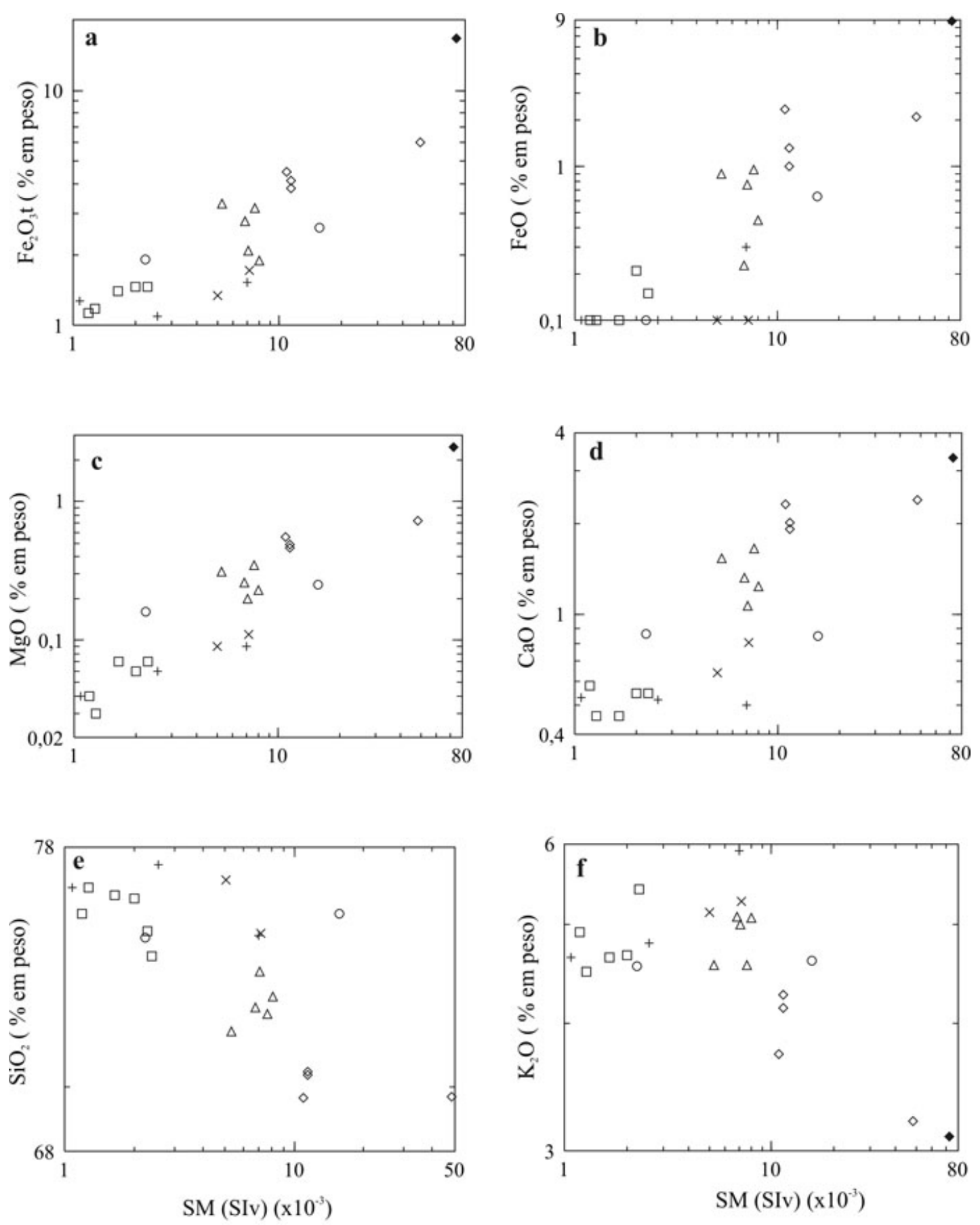

Figura 8 - Diagramas mostrando as relações entre o comportamento de SM e o conteúdo de: a) $\mathrm{Fe}_{2} \mathrm{O}_{3 t}$; b) $\mathrm{FeO}$; c) $\mathrm{MgO}$; d) $\mathrm{CaO}$; e) $\mathrm{SiO}_{2}$ ef) $\mathrm{K}_{2} \mathrm{O}$. Simbologia e siglas de acordo com a figura 3 .

Magalhães \& Dall'Agnol 1992, Oliveira et al. 2002, Figueiredo et al. 2003). Cristais homogêneos de Mt também ocorrem, entretanto, são mais raros.

Ilmenita A Ilmenita ocorre em todas as fácies do granito, porém é mais abundante nas fácies portadoras de anfibólio + biotita \pm clinopiroxênio (CBAMZG, BA$\mathrm{MzG}$ e $\mathrm{ABMzG}$ ) onde apresenta uma maior diversidade textural. Nos leucogranitos os cristais de ilmenita apresentam-se heterogêneos e fortemente transformados, sobretudo no centro dos cristais. De acordo com a terminologia definida por Buddington \& Lindsley (1964), Haggerty (1981) e Dall'Agnol et al. (1997) para descrever os tipos texturais de ilmenita, foram identificados:

1 - Ilmenita trellis ou treliça (Ilm T), correspondendo a lamelas provenientes de oxi-exsolução, Intercrescidas com magnetita (Fig. 10a);

2 - Ilmenita composite ou composta (Ilm C), corresponde a cristais de ilmenita em contato com Mt, seja interna (Ilm Cint; Figs. 9c,f) ou externamente (Ilm Cext; Figs. 9d,10d); 



Figura 9 - Fotomicrografias (luz refletida e nicóis paralelos) dos minerais óxidos de Fe e Ti do Granito Bannach, mostrando seus principais aspectos texturais. a) Cristal hipidiomórfico de magnetita (Mt) sem evidência de oxidação, incluso em biotita (Bt) (a,b,c = biotita-anfibólio-monzogranito grosso); b) Cristal de magnetita intercrescido com Ilmenita trellis (Ilm T) com martitização (Mrt) moderada (Leucomonzogranito grosso); c) Cristal de Ilmenita do tipo composta interna (Ilm Cint) associada com magnetita incipientemente martitizada; d) Cristais de ilmenita dos tipos individual (Ilm I) e composta externa (Ilm Cext), sendo que o último está associado à magnetita moderadamente oxidada; e) Cristal de Ilmenita do tipo sanduiche (Ilmenita S) no centro de cristal de magnetita (e, $f=$ anfibólio-biotita-monzogranito grosso); f) Cristal irregular de Ilmenita do tipo composta interna (Ilm CInt) ocorrendo na porção central da magnetita.

3 - Ilmenita Individual (Ilm I) são cristais que não estão intercrescidos ou em contato com a Mt (Figs. 9d,10c); 4 - Ilmenita Sanduiche (Ilm S), presente como faixas contínuas no interior da magnetita (Fig. 9e).

5 - Ilmenita Patch ou em manchas (Ilm P), presente como manchas irregulares no interior da magnetita (Fig. 10b), provavelmente associados aos processos de oxi-exsolução.
A Ilm T desenvolve-se em até três planos distintos em um mesmo cristal de magnetita (Buddington \& Lindsley 1964, Haggerty 1981). Como visto anteriormente, a formação dos intercrescimentos de magnetita e Ilmenita em treliça é atribuída à transformação da titanomagnetita através de processos de oxidaçãoexsolução. Segundo Buddington \& Lindsley (1964), essa transformação ocorre a temperaturas $(\mathrm{T})$ inferiores 

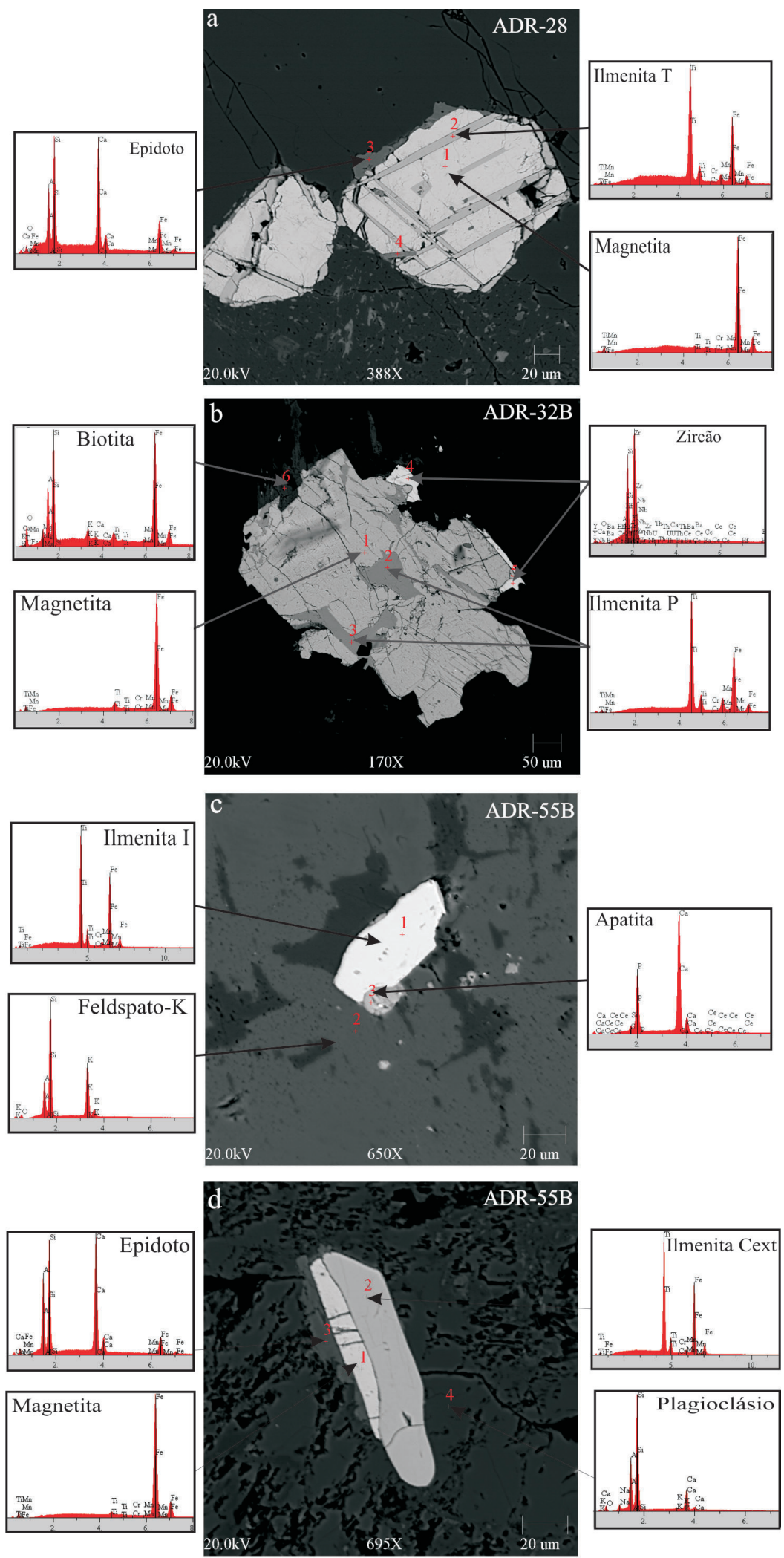

Figura 10 - Imagens de elétrons retro-espalhados obtidas em microscópio eletrônico de varredura, acompanhadas de espectros de EDS dos principais fases minerais identificadas do Granito Bannach: a) Magnetita intercrescida com Ilmenita trellis, bordejada por epidoto; b) Intercrescimento entre magnetita e ilmenita em treliça e em manchas, associado com biotita e zircão; c) Cristal de ilmenita individual incluso em feldspato potássico e associado com apatita; d) Ilmenita composta externa associada com magnetita inclusas em plagioclásio e circundada porparcialmente por epidoto. 
a $620^{\circ} \mathrm{C}$, caracterizando uma reação no estágio subsolidus. Porém, Haggerty (1981) considera que ela possa ser iniciada ainda no estágio magmático. De qualquer modo, a reação envolvida seria:

$$
6 \mathrm{Fe}_{2} \mathrm{TiO}_{4}+\mathrm{O}_{2} \longrightarrow 2 \mathrm{Fe}_{3} \mathrm{O}_{4}+6 \mathrm{FeTiO}_{3}
$$

Os tipos texturais de ilmenita, bem como as associações com outros minerais, identificados nos estudos petrograficos, foram confirmadas pelas observações e análises no MEV. Os espectros de raios-x obtidos por meio de EDS, demonstram que as composições da ilmenita em treliça e em manchas são muito similares (Tab. 3; Figs. 10a e b, respectivamente). Isto juntamente com as evidências texturais, sugere contemporaneidade entre esses tipos texturais de ilmenita, cuja origem estaria relacionada aos processos de oxidação-exsolução da titanomagnetita primária. Um raciocínio análogo é aplicado para a ilmenita do tipo S.

As Ilmenita dos tipos individual e composta (Figs. 10c e d, respectivamente) possuem composições semelhantes, apresentando, porém, conteúdos de Mn significativamente inferiores aos dos cristais de ilmenita em treliça e em manchas. O estudo composicional detalhado dos minerais óxidos de Fe e Ti do Granito Jamon (Dall'Agnol et al. 1997) revelou que as ilmenitas individual e composta muito provavelmente eram de origem magmática, enquanto que as ilmenitas em treliça e em mancha resultaram do processo de oxi-exsolução da titanomagnetita e se formaram mais tardiamente. Os dois conjuntos mencionados se distinguiam por aspectos texturais e pelo conteúdo mais elevado de $\mathrm{MnO}$ nas ilmenitas tardias, tal como se verifica no caso do Granito Bannach.

São comuns grãos de ilmenita individual xenomórficos envolvidos por coroas de titanita, sugerindo substituição parcial dos mesmos. Essa relação é observada também no caso de cristais de ilmenita composta, o que reforça sua origem magmática. A magnetita também apresenta localmente bordas de titanita, mas as mesmas são menos desenvolvidas que no caso da ilmenita.

Hematita (Martita) Está presente em todas as fácies, porém com conteúdo variável, e geralmente muito pequeno, sempre substituindo a magnetita, por meio do processo de martitização, comumente desenvolvendose ao longo dos seus planos $\{111\}$. São mais freqüentes nas fácies leucograníticas, cristais de magnetita inteiramente substituídos por martita, sugerindo uma relação entre a intensidade do processo de martitização e o estágio de diferenciação magmática. Segundo Haggerty (1981), o processo de martitização ocorre sobre cristais de Mt pobres em Ti. Isto é coerente com o observado, uma vez que o desenvolvimento da martita ocorre preferencialmente ao longo dos planos de contato entre magnetita e ilmenita em treliça, sugerindo que a martita é posterior ao processo de oxi-exsolução que afetou a titanomagnetita original. $\mathrm{O}$ baixo teor de Ti na magnetita das diferentes fácies do Granito Bannach foi compro- vado através de análises de MEV (Tab. 3). Com base nisto e na T mínima de formação da ilmenita em treliça (Lindsley 1981, Spencer \& Lindsley 1981), admite-se que a martita tenha se formado em T inferiores a $620^{\circ} \mathrm{C}$ e, portanto, também em condições subsolidus.

Goethita Este mineral ocorre em quantidades modais muito reduzidas e em apenas algumas rochas estudadas. Encontra-se substituindo a pirita nas bordas de seus cristais. A formação de goethita pode resultar de processos de oxihidratação de magnetita e pirita. Porém, nas amostras estudadas a goethita está ligada unicamente aos processos de oxidação da pirita.

\section{Evolução dos minerais opacos do Granito Ban-na-} ch De acordo com Almeida (2005) e Almeida et al. (2006), as evidências texturais apontam que os minerais opacos ocorrem freqüentemente como inclusões nas principais fases minerais. A figura 11 ilustra a seqüência de formação dos minerais opacos ao longo da evolução do magma Bannach. Ela mostra três estágios principais de cristalização:

1 - magmático: evidências texturais mostram que a ilmenita e magnetita são as fases cristalizadas precocemente. Nas fácies menos evoluídas, mais ricas em máficos, ambas ocorrem como inclusões em clinopiroxênio, anfibólio, plagioclásio, biotita e, mais raramente, K-feldspato. Nestas fácies, a ilmenita é encontrada como inclusões idiomórficas em clinopiroxênio e anfibólio. Tais evidências texturais e o fato de a ilmenita apresentar-se sem inclusões, ao passo que a magnetita comumente possui inclusões de apatita e zircão, sugerem que a titanomagnetita é ligeiramente posterior a zircão, apatita, ilmenita.

2 - tardi-magmático: este estágio é marcado pela formação de titanita. Como visto anteriormente, as ilmenitas individual e composta externa e a magnetita às vezes mostram franjas de titanita, sugerindo a desestabilização das mesmas e suas substituições parciais com a utilização de titânio para a formação de titanita. $\mathrm{O} \mathrm{Ca}$ e Si, também necessário para a sua formação, podem ser provenientes da reação peritética de desestabilização do anfibólio (Dall'Agnol et al. 1999) ou do próprio líquido magmático.

3 - pós-magmático: este estágio é caracterizado inicialmente pela formação de intercrescimentos de magnetita e Ilmenita em treliça, em manchas e sanduíche. Em mais baixas temperaturas dá-se a substituição da magnetita pela martita e da pirita pela Goethita. A intensidade de substituição aumenta das fácies portadoras de anfibólio + biotita \pm clinopiroxênio em direção aos leucogranitos. O momento de cristalização dos sulfetos (pirita, calcopirita e esfalerita) não pode ser determinado, mas correspondem provavelmente a fases subsolidus.

As evidências texturais indicam que a associação de minerais opacos primária desse granito é formada por ilmenita individual e composta e titanomagnetita, e esta atualmente representada pelos intercrescimentos de magnetita + ilmenita em treliça, em manchas e 
Tabela 3 - Composições químicas semi-quantitativas dos minerais óxidos de Fe e Ti.

\begin{tabular}{|c|c|c|c|c|c|c|c|}
\hline \multicolumn{2}{|c|}{ Amostra ADR-28 } & \multicolumn{2}{|c|}{ Amostra ADR-32 } & \multicolumn{2}{|c|}{ Amostra ADR-55B } & \multicolumn{2}{|c|}{ Amostra ADR-55B } \\
\hline \multicolumn{2}{|c|}{$\begin{array}{c}\text { Figura 10a- } \\
\text { Espectro } 1(\mathrm{Mt})\end{array}$} & \multicolumn{2}{|c|}{$\begin{array}{c}\text { Figura 10b - Espectro } 1 \\
(\mathrm{Mt})\end{array}$} & \multicolumn{2}{|c|}{$\begin{array}{c}\text { Figura } 10 \mathrm{c}- \\
\text { Espectro } 1(\mathrm{Ilm} \mathrm{I})\end{array}$} & \multicolumn{2}{|c|}{$\begin{array}{c}\text { Figura 10d - } \\
\text { Espectro } 2(\text { Ilm Cext. ) }\end{array}$} \\
\hline $\mathrm{FeOt}$ & 99,260 & $\mathrm{FeOt}$ & 97,420 & $\mathrm{FeOt}$ & 49,387 & $\mathrm{FeOt}$ & 48,728 \\
\hline $\mathrm{MnO}$ & 0,068 & $\mathrm{MnO}$ & 0,145 & $\mathrm{MnO}$ & 1,791 & $\mathrm{MnO}$ & 1,344 \\
\hline $\mathrm{Cr}_{2} \mathrm{O}_{5}$ & 0,056 & $\mathrm{Cr}_{2} \mathrm{O}_{5}$ & 0,039 & $\mathrm{Cr}_{2} \mathrm{O}_{5}$ & 0,008 & $\mathrm{Cr}_{2} \mathrm{O}_{5}$ & 0,024 \\
\hline $\mathrm{TiO}_{2}$ & 0,617 & $\mathrm{TiO}_{2}$ & 2,397 & $\mathrm{TiO}_{2}$ & 48,813 & $\mathrm{TiO}_{2}$ & 49,904 \\
\hline Total & 100,000 & Total & 100,000 & Total & 100,000 & Total & 100,000 \\
\hline \multicolumn{2}{|c|}{$\begin{array}{c}\text { Figura } 10 \mathrm{a}- \\
\text { Espectro } 2(\mathrm{Ilm} \mathrm{T})\end{array}$} & \multicolumn{2}{|c|}{$\begin{array}{c}\text { Figura } 10 \mathrm{~b}- \\
\text { Espectro } 2 \text { e } 3(\mathrm{Ilm} \mathrm{P})\end{array}$} & \multicolumn{2}{|c|}{$\begin{array}{c}\text { Figura 10d- } \\
\text { Espectro } 1(\mathrm{Mt}) \\
\end{array}$} & & \\
\hline $\mathrm{FeOt}$ & 45,571 & $\mathrm{FeOt}$ & 42,299 & $\mathrm{FeOt}$ & 98,765 & & \\
\hline $\mathrm{MnO}$ & 4,051 & $\mathrm{MnO}$ & 7,283 & $\mathrm{MnO}$ & 0,019 & & \\
\hline $\mathrm{Cr}_{2} \mathrm{O}_{5}$ & 0,097 & $\mathrm{Cr}_{2} \mathrm{O}_{5}$ & 0,014 & $\mathrm{Cr}_{2} \mathrm{O}_{5}$ & 0,033 & & \\
\hline $\mathrm{TiO}_{2}$ & 50,280 & $\mathrm{TiO}_{2}$ & 50,404 & $\mathrm{TiO}_{2}$ & 1,184 & & \\
\hline Total & 100,000 & Total & 100,000 & Total & 100,000 & & \\
\hline
\end{tabular}

sanduíche. As fases secundárias são representadas por martita e goethita.

Com base nas relações texturais, propõem-se a seguinte seqüência de formação e evolução dos minerais opacos (Fig. 11):

1. Cristalização precoce de ilmenita individual e composta e titanomagnetita;

2. Atuação de processo de oxi-exsolução sobre cristais de titanomagnetita, produzindo intercrescimentos de magnetita empobrecida em Ti com ilmenita em treliça, em manchas e sanduíche.;

3. Desestabilização parcial da Ilm individual dando origem à titanita;

4. Martitização da magnetita;

5. Oxidação da pirita gerando cristais de goethita.
A pressão total $(\mathrm{P})$ e a temperatura $(\mathrm{T})$ decrescem de 1 para 5 , enquanto a fugacidade de oxigênio $\left(f \mathrm{O}_{2}\right)$ apresenta um aumento relativo, considerando as diferentes curvas tampões.

DISCUSSÕES E CONCLUSÕES A análise dos dados de SM do Granito Bannach permitiu identificar cinco populações (A, B, C, D e E), com diferentes características magnéticas, as quais se correlacionam coerentemente com a evolução magmática do corpo. Os valores mais altos de SM relacionam-se às fácies menos evoluídas, relativamente ricas em anfibólio, enquanto os valores mais baixos ocorrem nas fácies leucograníticas com maior conteúdo de sílica. De modo geral, as amostras das fácies mais ricas em anfibólio concentram-se

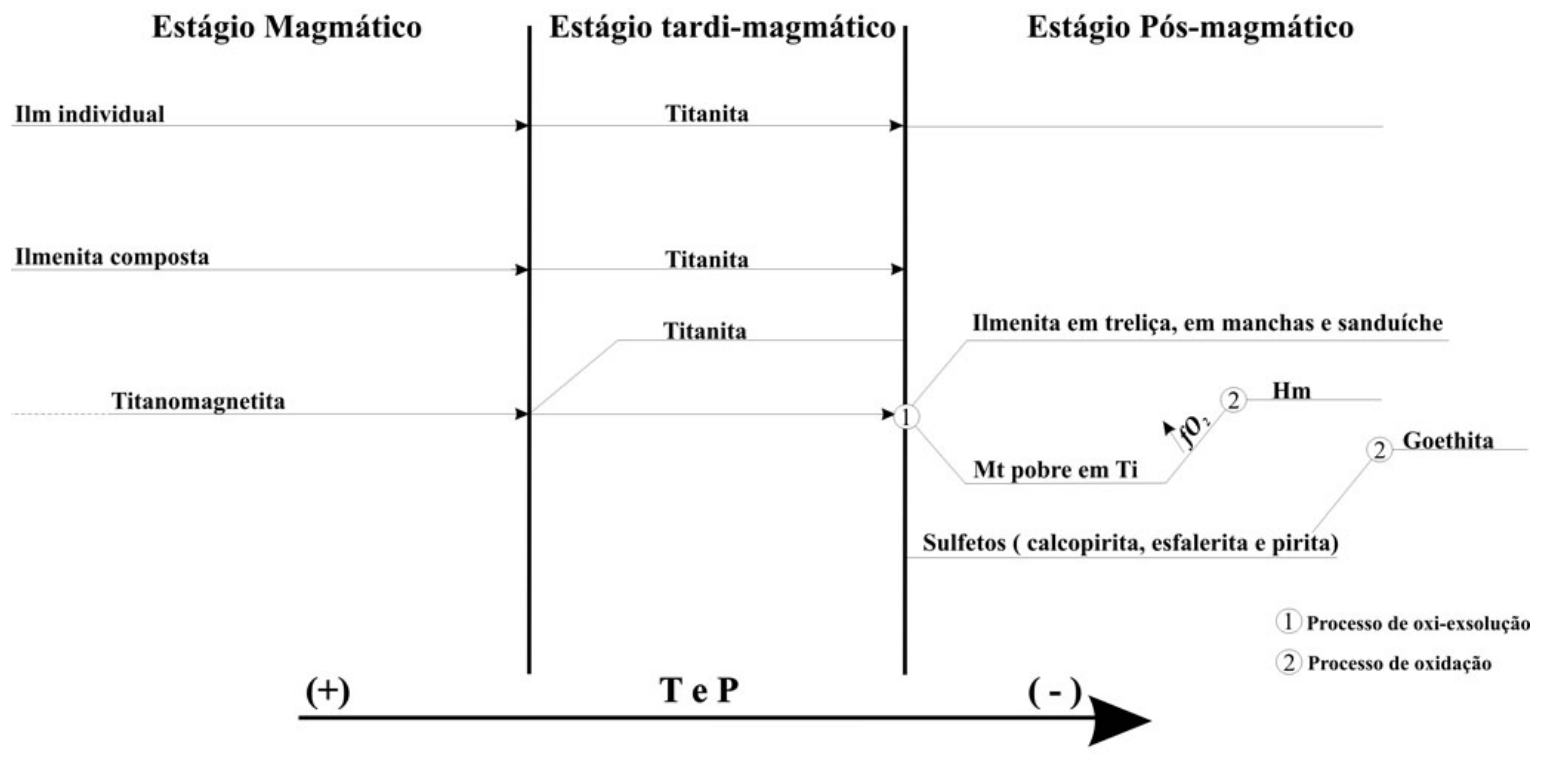

Figura 11- Ordem de cristalização dos minerais opacos do Granito Bannach. 
nas populações E, D e C de mais alta SM, sendo que os valores intermediários, correspondentes à população $\mathrm{B}$, são observados nas rochas onde a biotita predomina sobre o anfibólio. Os menores valores de SM, correspondentes à população $\mathrm{A}$, associam-se aos leucogranitos.

Há uma boa correlação positiva entre SM e os conteúdos de minerais opacos e anfibólio, refletindo o fato dessas fases terem sido formadas em estágio magmático relativamente precoce. Também há, de modo geral, uma correlação positiva entre SM e máficos e biotita embora menos consistente que com opacos e anfibólio. As relações entre $\mathrm{SM}$ e as composições químicas das diferentes fácies revelam decréscimo de $\mathrm{Fe}_{2} \mathrm{O}_{3}$, $\mathrm{FeO}, \mathrm{MgO}, \mathrm{CaO}$, e de SM durante a diferenciação magmática, havendo uma nítida correlação positiva entre SM e esses óxidos.

O Granito Bannach apresenta valores relativamente elevados de $\mathrm{SM}\left(>1,078 \times 10^{-3}\right)$ e das razões $\mathrm{Fe}_{2} \mathrm{O}_{3} / \mathrm{FeO}$, bem como do conteúdo modal de minerais opacos $(>0,1 \%)$ com uma presença marcante de magnetita em todas as suas fácies. Essas características permitem classificá-lo como um granito da série magnetita (Ishihara 1981). No diagrama discriminante da figura 12, foram plotados os dados de SM e dos conteúdos modais de opacos do Granito Bannach, juntamente com outros corpos da Suíte Jamon (Jamon, Musa e Redenção). Observa-se que os mesmos incidem no campo dos granitos da série magnetita. Outro fator que aproxima o maciço Bannach desses corpos é a similaridades em termos de evolução dos minerais óxidos de Fe e Ti.

Os principais minerais óxidos de $\mathrm{Fe}$ e Ti formados durante o estágio precoce da cristalização do magma Bannach são titanomagnetita, ilmenita individual e ilmenita composta. Esses cristais de ilmenita mostram- se, por vezes, substituídos parcialmente por titanita. Os demais tipos texturais de ilmenita (ilmenita em treliça, em manchas e sanduíche) juntamente com a magnetita pobre em titânio, foram originados no estágio subsoli$d u s$ por processos de oxi-exsolução de cristais de titanomagnetita originais. Em condições mais elevadas de fugacidade de oxigênio e a mais baixas temperaturas, a magnetita pobre em titânio foi afetada por processos de martitização, dando origem a hematita. A intensidade deste processo varia nas diferentes fácies, ou mesmo dentro de uma mesma fácies, podendo ser pouco expressivo ou, em casos extremos, levar a martitização total da magnetita.

O geotermômetro e o oxibarômetro baseado na composição das soluções sólidas ulvoespinéliomagnetita e ilmenita-hematita, em equilíbrio, tem sido empregado para quantificar as condições de fugacidade de oxigênio $\left(\mathrm{fO}_{2}\right)$ e a temperatura de formação de tais minerais. Porém, no granito estudado, além de não se dispor da composição quantitativa dos minerais óxidos de $\mathrm{Fe}$ e Ti, as transformações a que foram submetidos não permitiriam reconstituir as composições dos pares ilmenita-titanomagnetita formados durante o estágio magmático (cf. Dall'Agnol et al 1997). Logo, as estimativas de $\mathrm{fO}_{2}$ devem se basear em dados indiretos, como, por exemplo, a natureza dos minerais óxidos de Fe e Ti das diversas fácies. Wones (1989) mostrou o significado da $\mathrm{fO}_{2}$ das assembléias de minerais óxidos de Fe e Ti em rochas graníticas e revelou que a paragênese titanita (idiomórfica) + magnetita + quartzo é indicativa de condições oxidantes e de fugacidade de oxigênio $\left(\mathrm{fO}_{2}\right)$ relativamente elevada. Paragêneses semelhantes, formadas no estágio magmático, foram observadas nas diversas fácies do Granito Bannach, indicando que



Figura 12 - Relação entre conteúdo modal de opacos e suscetibilidade magnética dos granitos Bannach, Jamon, Musa e Redenção, mostrando que estes granitos incidem no campo dos granitos da série magnetita (Ishirara 1981). 
suas rochas se originaram de um magma que evoluiu em condições relativamente oxidantes. A associação de magnetita e titanita em todas as fácies demonstra que as condições reinantes durante a cristalização situam-se entre os tampões HM e FMQ, podendo serem estimadas para a cristalização condições de $\mathrm{fO}_{2}$ próximas às do tampão HITMQ (Wones 1989) e pouco acima das do tampão NNO (Frost 1991). Este raciocínio é fortalecido pela similaridade entre os granitos Bannach e Jamon. Neste último, estudos de minerais óxidos de Fe e Ti são experimentais (Dall'Agnol et al. 1997, 1999) demonstraram que a cristalização se deu em condições análogas àquelas estimadas para o Granito Bannach.

As transformações pós-magmáticas dos minerais óxidos de $\mathrm{Fe}$ e Ti, em particular a martitização da magnetita, principalmente nas fácies mais leucocráticas, sugerem que a $\mathrm{fO}_{2}$ deva ter crescido durante o estágio subsolidus, talvez por conta do crescimento do teor de voláteis. As associações minerais formadas neste estágio indicam que condições situadas acima do tampão HM devem ter sido atingidas, pelo menos localmente, para justificar a martitização da magnetita. Este processo de oxidação teria sido favorecido nas fácies leuco- graníticas, por derivarem de líquidos mais evoluídos e mais ricos em voláteis.

Agradecimentos Agradecemos aos pesquisadores do Grupo de Pesquisa Petrologia de Granitóides (GPPGCG-UFPA) pelo apoio nas diversas etapas deste traba1ho, em especial ao professor Cláudio Nery Lamarão pela realização das análises de MEV, ao doutorando Davis Carvalho de Oliveira pela colaboração nas diferentes etapas de estudo do corpo Bannach e a mestranda Fernanda Giselle Cruz do Nascimento pela obtenção de dados no Laboratório de Petrologia Magnética; à CAPES pela concessão da bolsa de mestrado ao primeiro autor (José de Arimatéia Costa de Almeida); Ao PIBIC-CNPq pela bolsa de iniciação científica concedida a Fabriciana Vieira Guimarães; Ao CNPq pela bolsa de produtividade em pesquisa (Roberto Dall'Agnol); ao Centro de Geociências (CG-UFPA) pelo suporte técnico; ao CNPq pelo apoio ao desenvolvimento da pesquisa (55.0739/01-7, 476075/03-3). Este artigo é uma contribuição para o projeto PRONEX/CNPq (Proj. 103/98 - Proc. 66.2103/1998-0) e IGCP - 510 (IUGS - UNESCO).

\section{Referências}

Almeida J.A. C. 2005. Geologia, Petrografia e Geoquímica do Granito Anorogênico Bannach, Terreno GranitoGreenstone de Rio Maria-Pará. Dissertação de Mestrado, Centro de Geociências, Universidade Federal do Pará, 170p.

Almeida J.A.C., Dall'Agnol R, Oliveira D.C. 2006. Geologia, Petrografia e Geoquímica do Granito Anorogênico Bannach, Terreno Granito-Greenstone de Rio Maria, Pará. Revista Brasileira de Geociências, 36:282-295.

Althoff F.J., Barbey P., Boullier A.M. 2000. 2.8-3.0 Ga plutonism and deformation in the SE Amazonian craton: the Archean granitoids of Marajoara (Carajás Mineral province, Brazil). Precambrian Research, 104:187-206. Anderson J.L. \& Morrison J. 2005. Ilmenite, magnetite, and peraluminous Mesoproterozoic anorogenic granites of Laurentia and Baltica. Lithos, 80:45-60.

Barbosa A.A., Lafon J.M., Neves A.P., Vale A.G. 1995. Geocronologia $\mathrm{Rb}-\mathrm{Sr}$ e $\mathrm{Pb}-\mathrm{Pb}$ do Granito Redenção, SE do Pará: Implicações para a evolução do magmatismo Proterozóico da região de Redenção. Boletim do Museu Paraense Emílio Goeldi, Série Ciências da Terra, 7:147164.

Buddington A.F. \& Lindsley D.H. 1964. Iron-Titanium oxide minerals and synthetic equivalents. Journal of Petrology, 5(2): 310-357.

Clark D. A. 1999. Magnetic Petrology of igneous intrusions: implications for exploration and magnetic interpretation. Exploration Geophysics, 30:5-26.

Collins W.J., Beams S.D., White A.J., Chappell B.W., 1982. Nature and origin of A-type Granites with particular reference to Southeastern Australia. Contributions to Mineralogy and Petrology 80:189-200.

Dall'Agnol R. 1980. Etudes sur des granites du type “ Ron- donian” en Amazonie Orientale et leurs transformations tardi-magmatiques. Tese de Doutoramento, Laborotoire de Géologie et Petrologia, Université Paul Sabatier, $348 \mathrm{p}$.

Dall'Agnol R. \& Oliveira D.C.O. 2007. Oxidized, magnetite-series, rapakivi-type granites of Carajás, Brazil: Implications for classification and petrogenesis of A-type granites. Lithos 93:215-233.

Dall'Agnol R., Pichavant M., Champenois M. 1997. IronTitanium Oxide Minerals of the Jamon Granite, Eastern Amazonian Region, Brazil: Implications for the Oxigen Fugacity in Proterozoic, A-type Granites. Anais da Academia Brasileira de Ciências, 69(3):325-347.

Dall'Agnol R., Scaillet B., Pichavant M. 1999. Evolution of A-type granite magmas: an experimental study of the Lower Proterozoic Jamon Granite, eastern Amazonian craton, Brazil. Journal of Petrology. 40(11):1673-1698.

Dall'Agnol R., Teixeira N.P., Rämö O.T., Moura C.A.V., Macambira M.J.B., Oliveira D.C.O. 2005. Petrogenesis of the Paleoproterozoic Rapakivi A-type granites of the Archean Carajás Metallogenetic Province, Brazil. Lithos. 80:101-129.

Dall'Agnol R., Oliveira M.A., Almeida J.A.C., Althoff F.J., Leite A.A.S., Oliveira D.C., Barros C.E.M., 2006. Archean and Paleoproterozoic granitoids of the Carajás metallogenetic province, eastern Amazonian Craton. In: R. Dall'Agnol, L.T. Rosa- Costa, E.L. Klein (eds.) Symposium on Magmatism, Crustal Evolution and Metallogenesis of the Amazonian Craton. Abstracts Vol. and Field Trips Guide. Belém, PRONEX-UFPA/ SBG-NO, $150 \mathrm{p}$.

Eby G.N. 1992. Chemical subdivision of the A-type granitoids: Petrogenetic and tectonic implications. Geology, 
20:641-644.

Figueiredo M.A.B.M., Dall'Agnol R., Lamarão C.N., Oliveira D.C. 2003. Petrologia Magnética do Granito São Jorge Antigo, Província Aurífera do Tapajós. Revista Brasileira de Geociências, 33(2):149-158.

Gastal M.C.P. 1987. Petrologia do Maciço Granítico Musa, sudeste do Pará. Dissertação de Mestrado, Centro de Geociências, Universidade Federal do Pará, 316 p.

Haggerty S.E. 1981. Oxidation of opaque mineral oxides in basalts. In: D.Rumble III (ed.) Oxide minerals. 2nd ed. Washington, Miner. Soc. Am. P. Hg1-Hg99. (Short course notes).

Huhn S.R.B., Santos A.B.S., Amaral A.F., Ledsham E.J., Gouveia J.L., Martins L.B.P., Montalvão R.M.G., Costa V.G. 1988. O Terreno Granito-Greenstone da região de Rio Maria - Sul do Pará. In: SBG, Congresso Brasileiro de Geologia, 35, Belém, Anais, v. 3, p. 1438-1453.

Ishihara S. 1981. The granitoid series and mineralization. In: B.J Skinner (ed.) Economic Geology, 75th anniversary Volume, p.458-484.

King P.L., Chappell, B.W., Allen, C.M., White, A.J.R. 2001. Are A-type granite the high-temperature felsic granite? Evidence from fractionated granite of the Wangrah Suite. Australian $\mathrm{Jl}$. of Earth Sciences, 48:501-514.

Le Maitre R.W. 2002. Igneous Rocks: A Classification and Glossary of Terms. 2nd Edition, London, 193p.

Leite A.A.S. 2001. Geoquímica, petrogênese e evolução estrutural dos Granitóides Arqueanos da Região de Xinguara, SE do Cráton Amazônico. Tese de Doutoramento, Centro de Geociências, Univ Federal do Pará, 330p.

Leite A.A.S., Figueiredo M.A.B.M., Dall'Agnol R. 1997. Comportamento magnético e natureza dos minerais opacos do Maciço Granítico Arqueano Xinguara, sudeste do Pará. In: M.L.Costa, R.S. Angélica (eds). Contribuições à Geologia da Amazônia. Belém, FINEP/SBG. Núcleo Norte. p. 205-222.

Lindsley D.H. 1981. Some experiments pertaining to the magnetite-ulvöspinel miscibility gap. American Mineralogist, 66:759-762.

Loiselle M.C., Wones D.R., 1979. Characteristics and origin of anorogenic granites. Geological Society of America Abstracts with Programs, 11:468.

Machado N., Lindenmayer Z., Krogh T.E., Lindenmayer D. 1991. U/Pb geochronology of Archean magmatism and basement reactivation in the Carajás Área, Amazon Shield, Brazil. Precambrian Research, 49:329-354.
Magalhães M.S \& Dall'Agnol, R. 1992. Estudos de minerais opacos e suscebilidade magnética nos Granitos Musa e Jamon (Região de Rio Maria - SE do Pará) e suas implicações petrológicas. Revista Brasileira de Geociências, Belém, 22:2.

Nascimento F.G.C. 2006. Petrologia magnética das associações magmáticas arqueanas da Região de Canaã dos Carajás - PA. Belém. Dissertação de Mestrado, Centro de Geociências, Universidade Federal do Pará, 177 p.

Oliveira D.C. 2001. Geologia, geoquímica e petrologia magnética do granito anorogênico Redenção, sudeste do Estado do Pará. Dissertação de Mestrado, Centro de Geociências, Universidade Federal do Pará, 206p.

Oliveira D.C. 2006. Modelos de Evolução e Colocação dos Granitos Paleoproterozóicos da Suíte Jamon, SE do Cráton Amazônico. Tese de Doutoramento, Instituto de Geociências, Universidade Federal do Pará, 186p.

Oliveira D.C., Dall'Agnol R., Barros C.E.M., Figueiredo M.A.B.M., 2002. Petrologia magnética do Granito Paleoproterozóico Redenção, SE do Cráton Amazônico. In: E.L Klein, M.L. Vasquez, L.T. Rosa-Costa (eds.) Contribuições à Geologia da Amazônia. Sociedade Brasileira de Geologia Núcleo Norte, Belém, vol. 3, p. 115-132.

Pearce J.A., Harris N.B.W., Tindle A.G. 1984. Trace Element Discrimination Diagrams for the tectonic interpretation of granitic rocks. Journal of Petrology., 25:956-983.

Souza Z.S. 1994. Geologia e petrogênese do "Greenstone Belt" Identidade: implicações sobre a evolução geodinâmica do terreno granito- "greenstone" de Rio Maria, $S E$ do Pará. Tese de Doutoramento, Centro de Geociências, Universidade Federal do Pará, 624p.

Spencer K.J. \& Lindsley D.H. 1981. A solution model for coexisting iron-titanium oxides. American Mineralogist, 66:1189-1201.

Whalen J.W., Currie K.L., Chappel B.W. 1987. A-type granites: geochemical characteristics, discrimination and petrogenesis. Contributions to Mineralogy and Petrology, 95:407-419.

Wones D.R. 1989. Significance of the assemblage titanite + magnetite + quartz in granitic rocks. American Aineralogist, 74: 744-749.

Manuscrito AE-054/2006

Recebido em 30 de outubro de 2006 Aceito em 08 de fevereiro de 2007 